Check for updates

Cite this: RSC Adv., 2020, 10, 7468

\title{
Effect of structural factors on the physicochemical properties of functionalized polyanilines
}

\author{
Anastasiia N. Andriianova, (D) *a Yuliya N. Biglova (D) ${ }^{b}$ and Akhat G. Mustafina \\ This review discusses the physical and physicochemical properties of polyaniline (PANI) derivatives. The \\ most important methods for the preparation of functionalized polyanilines are presented. The presence \\ of various substituents in its structure changes the polymer characteristics significantly due to steric and \\ electronic effects of the functional groups. This review describes the relationship between the properties \\ of functionalized polyanilines depending on the nature, number and position of the substituents at the \\ aromatic ring.
}

Received 22nd October 2019

Accepted 29th January 2020

DOI: $10.1039 / \mathrm{c} 9 \mathrm{ra} 08644 \mathrm{~g}$

rsc.li/rsc-advances magnetic characteristics and their morphology differs fundamentally. This uncertainty inspires scientific teams, both in Russia and abroad, to deal with the following tasks of current interest: development of methods for controlled synthesis of PANI to provide target products with predefined morphology and properties; use of functionalized anilines in the polymerization process to improve the product performance; expanding the range of electrically conductive macromolecular compounds using functionalized anilines in order to identify efficient electroactive representatives.

Modified PANI can be synthesized in a number of ways:

(1) Polymerization of aniline pre-modified at the aromatic ring or at the amino group; ${ }^{17-19}$

(2) Polymer-analogous conversion of PANI (incorporation of functional groups into a polymer obtained previously); ${ }^{\mathbf{2 0 , 2 1}}$

(3) Copolymerization of aniline and derivatives based on $\mathrm{it}^{22-25}$

\section{(4) PANI doping. ${ }^{26}$}

Thermogravimetric studies of PANI derivatives containing various doping agents have shown that in the temperature range of $50-100{ }^{\circ} \mathrm{C}$, the counterion escapes from the polymer. ${ }^{22}$ This affects PANI properties significantly, since the loss of the doping agent impairs its key property, viz., electric conductivity. Although doping improves the operational characteristics of the polymer, however, the accompanying decrease in heat resistance significantly limits the field of its practical applications.

The polymer-analogous conversions of PANI are rather poorly covered in scientific literature, apparently due to the fact that the polymer almost does not allow recycling. Nevertheless, several attempts were made to incorporate substituents into the aromatic ring in the PANI macromolecular chain. ${ }^{20,21,27}$ It should be understood in this case that upon incomplete conversion of the starting compound, polymers with varying chain lengths, irregular structures and unsatisfactory target properties are very likely to be obtained. 
The most promising method for PANI modification involves the functionalization of the initial monomer by introducing substituents in order to synthesize mono- or disubstituted aniline derivatives, followed by their polymerization. The intensification of studies in this direction aimed at the development of a variety of low molecular mass anilines for conversion to high molecular mass objects should be noted as a confirmation of the above considerations. ${ }^{17-19}$

This publication provides the most comprehensive review of literature sources on modified PANI over the past 20 years. The main methods and specifics of the polymerization of aniline derivatives are considered. A correlation between the nature, amount and position of substituents at the aromatic ring and the variation in the properties of polymers in comparison with unsubstituted PANI is given.

\section{Synthesis of polyaniline derivatives}

Functionalized PANI are usually obtained by chemical polymerization with oxidizing agents, ${ }^{28}$ by electrochemical deposition on working electrodes made of noble metals, ${ }^{29}$ various types of graphite and glass with an electrically conductive coatings, as well as by interface polymerization. The properties of the resulting high molecular mass product substantially depend on the experimental conditions, such as temperature, time, solvent, doping acid, and concentrations and nature of the reagents.

\subsection{Chemical synthesis}

The classical oxidative polymerization of aniline derivatives involves the monomer conversion in an aqueous solution of an acid as the doping agent, in the presence of oxidizing agents (potassium persulfate ${ }^{30}$ or ammonium persulfate, ${ }^{32,33}$ potassium dichromate, ${ }^{31}$ or iron(III) chloride ${ }^{34}$ ). As a rule, the polymerization process is performed in an acid environment at $\mathrm{pH}$ $0-2$. If salt formation with the monomer is hindered in aqueous acid solutions, organic solvents are used, such as DMF, DMSO, methanol, ${ }^{35}$ THF,${ }^{36}$ chloroform, ${ }^{37}$ various ethers, ${ }^{38,39}$ etc. Despite the apparent simplicity of aniline oxidative polymerization, it is a complex multi-stage reaction. It includes two interrelated processes: assembly of monomeric units resulting in the growth of macromolecules, and self-organization of the growing chains into supramolecular structures. The polymer chains in an electrically conductive PANI contain 95-98\% para-substituted monomeric units bound head-to-tail, thus providing a developed poly-conjugated system. ${ }^{2}$

The polymerization of aniline derivatives is performed similarly to the synthesis of unsubstituted PANI. The difference in the conditions required for synthesizing the target product is determined by the nature of the substituent at the aromatic ring of the starting monomer, since it affects the basicity of the modified aniline and incorporation of functional groups adversely affects its reactivity. According to literature sources, aniline derivatives containing electron-donating or weak electron-withdrawing groups form a stable free radical in the course of polymerization and the reaction occurs slowly. ${ }^{40}$ The situation is different if the monomer contains a strong electronwithdrawing substituent: the free radical is unstable and polymerization does not occur. ${ }^{41}$ Bearing in mind the results obtained in ref. 41 , the authors of ref. $42-44$ did the following to successfully convert a monomer into a high molecular mass compound: they "compensated" for some decrease in the electron density on the nitrogen atom due to the presence of an electron-withdrawing substituent by incorporating an electrondonating group into the aromatic ring. The problem of low reactivity of polymerization participants is successfully resolved using catalysts, for example, such as aniline and phenylenediamine dimers. ${ }^{45,46}$ To increase the yield of the target product, it was suggested ${ }^{47,48}$ to use catalysts such as alkali metal salts, lithium chloride in particular, for increasing the molecular mass.

Ultrasonic $^{49-56}$ or microwave radiation ${ }^{57-61}$ are used to improve the physicochemical properties of polymers and to increase the product yield in the oxidative polymerization of aniline and its functionalized derivatives. It is known that external irradiation of this kind makes it possible to obtain PANI derivatives in yields 2.5-3 times higher than the classical synthetic method, the synthesis time being 5-10 minutes. ${ }^{\mathbf{5 9 , 6 0}}$ The polymers that we isolated had a nanoscale supramolecular structure, improved electrical conductivity and higher molecular weights. ${ }^{61}$ The use of ultrasonic or microwave irradiation allows one to decrease the amount of the oxidizer, thus reducing the amount of side products and making PANI synthesis more environmentally friendly. ${ }^{53}$

\subsection{Electrochemical synthesis}

Since electrochemical methods for synthesizing polymers are advantageous in comparison with classical chemical methods, it is quite understandable that anodic oxidation of monomers on a working electrode is among the most common methods for converting low molecular mass compounds to high molecular mass compounds. The resulting product is "pure" and does not require isolation from the initial monomer/oxidant/solvent mixture. If this method of synthesis is used, it can be combined with physical spectroscopic methods (UV, IR, visible spectroscopy, Raman scattering, ellipsometry and conductometry) in order to determine the properties of the material in situ.

Electrochemical syntheses of PANI derivatives, which involve the deposition of a polymer onto a working electrode made of metals, ${ }^{29,62-72}$ carbon materials (glass carbon, graphite), or optically transparent electrodes made of glass coated with metals or metal oxides, ${ }^{37,70-74}$ are performed in galvanostatic, potentiostatic, or potentiodynamic modes in a three-electrode cell. A study of this process by scanning electron microscopy confirmed that the most homogeneous products are obtained in the potential cycling mode. ${ }^{76}$

The electrolytes commonly used in the syntheses of polymers include acids, such as $\mathrm{HClO}_{4}, \mathrm{H}_{2} \mathrm{SO}_{4}, \mathrm{HCl}, \mathrm{HBF}_{4}$, and $\mathrm{HF}$, as well as various buffer solutions. To convert substituted anilines insoluble in aqueous solutions of acids into high molecular 
mass products, a mixture of an aqueous acid solution (70\%) and an organic solvent, acetonitrile (30\%), is used. ${ }^{29}$

The substituents present in the aniline molecule affect the electrochemical process considerably: the electron-donating ones decrease the oxidation potential due to a decrease in the basicity of the nitrogen atom (alkyl and alkoxy groups), while the electron-withdrawing ones hinder the polymer formation. The latter results from an increase in the positive charge on the nitrogen atom and destabilizes it compared with aniline, thus decreasing the reactivity. For example, it was found in a number of studies that substituted aniline containing a sulfo and alkoxysulfo group did not undergo electropolymerization. ${ }^{35,75-77}$

In order to prevent the overoxidation of the polymer film, the anodic limit of the polymerization potential during the electrosynthesis of functionalized high molecular mass anilines is maintained at low values. At the initial stages of the process, the PANI film grows slowly, but after about 20 cycles this process accelerates significantly and approaches completion after 50 cycles at a scan rate of $10-100 \mathrm{mV} \mathrm{s}^{-1}$, which indicates its low electrical conductivity. ${ }^{63-70}$

\subsection{Interface polymerization}

Scientific literature contains rather few examples of the interface polymerization of aniline and its derivatives. Depending on the polymerization conditions, PANI can form a wide range of supramolecular structures. These are one-, two- and threedimensional particles, as well as complex hierarchical structures corresponding to different types of macromolecule packing. ${ }^{78}$ Upon completion of the synthesis, the resulting macromolecule agglomerates cannot be melted or dissolved; the polymer structure remains unchanged. Thus, the synthesis irreversibly "freezes" not only the molecular assembly of chains but also their supramolecular packaging.

As a rule, the interface polymerization is performed at room temperature. Aniline is dissolved in an organic solvent (chloroform, hexane), and an aqueous solution of an oxidizing agent (potassium dichromate, ammonium persulfate or peroxydisulfate, iron chloride) is gradually added with vigorous stirring to the monomer solution in order to initiate the polymerization. The formation of a greenish-blue precipitate is observed in $5-10$ minutes after the reaction is started. The synthesis is completed after 24 hours of stirring, then water is added to the reaction mixture in order to complete the precipitation. Some researchers prefer aqueous solutions of acids as solvents for the oxidizing agents. The yield of the target product in the synthesis described above is no higher than $50 \% .^{37,47,74-82}$ Despite the simplicity of the experiment, it appears that the low popularity of this method for synthesizing high molecular mass compounds is explained by the low product yields.

\section{Physicochemical properties of polyaniline derivatives}

As noted above, PANI has a unique set of properties that favor its widespread use in many areas of technology. Nevertheless, its extremely low solubility in typical organic solvents and the lack of adhesion to other materials significantly limits its practical use. Its another drawback is that due to the complexity of the synthesis of PANI samples with reproducible properties, the electrical conductivity of oxidative polymerization products differs by orders of magnitude. Therefore, it is of scientific and practical interest to study the effect of substituents on the set of properties of functionalized PANI in order to identify the most efficient representatives of this class of compounds.

\subsection{Solubility}

PANI belongs to poorly soluble compounds, but the situation changes upon incorporation of substituents at the monomer's aromatic ring.

The nature of the substituent may help improve the solubility in organic or inorganic media. ${ }^{38,40,47,48,74}$

It was noticed that incorporation of substituents that activate the ortho and para positions $\left(-\mathrm{CH}_{3},-\mathrm{OCH}_{3}\right)$ into PANI aromatic ring improved its solubility in polar solvents: DFMA, DMSO, $N$-methylpyrrolidone, methanol, ethanol, acetone, and partially in chloroform..$^{47,48,79,83}$ A significant improvement in solubility is observed for disubstituted PANI derivatives, e.g. with long alkoxy groups, up to $400 \mathrm{~g} \mathrm{l}^{-1}$ in water, $100 \mathrm{~g} \mathrm{l}^{-1}$ in acetonitrile, 50 and $40 \mathrm{~g} \mathrm{l}^{-1}$ in acetone and tetrahydrofuran, respectively. ${ }^{84}$ Experimental results demonstrated a beneficial effect of the presence of oxygen-containing groups on the solubility of functionalized PANI in polar media. Solubility improvement is achieved in the presence of other heteroatomcontaining substituents in the PANI macromolecule. In fact, halogen derivatives show an increase in solubility in strongly polar media $\left(\mathrm{H}_{2} \mathrm{SO}_{4}\right.$, DMF, DMSO, $N$-methyl-2-pyrrolidinone), ${ }^{24,85}$ while the thiophene substituent at the ortho position of the aromatic ring of PANI increases the solubility in nonpolar solvents. ${ }^{35}$ Although the increase in solubility in typical organic solvents is negligible for PANI with an unsubstituted amino group at the ortho position, it increases strongly in acidic media. $^{86}$

The presence of a doping agent drastically affects the properties of PANI. A good example is given by the solubility of the fully doped sulfo derivative of PANI: on reaching the maximum content of chlorosulfonic acid in the polymer, its solubility increases 4 -fold. ${ }^{87-89}$ Therefore, the groups framing the macromolecular chain are crucial for the solubility of functionalized PANI: they must be charged. Polymers of this type are called self-doped because the substituents act as a doping agent. The solubility of such PANI derivatives both in water and in organic media increases with an increase in the number of acid groups in the macromolecule's side chain, whereas the presence of anionic groups beneficially affects the solubility in bases. $^{75-77,89-94}$

One of the reasons for the solubility improvement is assumed $^{47,48}$ to lie in the formation of an oligomeric product due to the presence of a substituent that causes a kinetic effect and a decrease in the chain growth rate.

Thus, the presence of various substituents at the aromatic ring of the starting aniline affects the growth of the macromolecular chain and the molecular mass of the target product. The 
increase in the solubility of functionalized PANI should be attributed to the presence of $\mathrm{C}-\mathrm{R}$ bonds along the main polymer chain (where $\mathrm{R}$ is an electron-donor substituent: -Alk, -OAlk, -Hal, etc.), which results in an increase in the macromolecule flexibility in comparison with the rigid PANI structure. ${ }^{24}$

\subsection{Electrochemical properties}

PANI shows redox activity. ${ }^{48}$ Electron transfer processes occur under the action of oxidizing/reducing agents or upon application of a potential to an electrode modified with a polymer. It is known that three stable oxidation states are characteristic of PANI (Scheme 1), as the cyclic voltammogram (CV) of the polymer shows (Fig. 1).

The maxima on the $\mathrm{CV}$ correspond to transitions between the oxidized forms. Emeraldine is the most stable form of PANI (from +0.2 to $+0.8 \mathrm{~V}$ ) (Scheme $1 \mathrm{~b}$ ), and at potential values below $+0.2 \mathrm{~V}$ it is in fully reduced state, i.e., in the form of leucoemeraldine (Scheme 1a). Pernigraniline, which exists at potentials above $+0.8 \mathrm{~V}$ (Scheme 1c), appears to be the most oxidized form of PANI. If the applied potential increases above $+0.8 \mathrm{~V}$, the polymer undergoes irreversible changes ${ }^{95}$ that often give a third peak on the CV. The latter phenomenon indicates the loss of electroactivity by PANI observed upon overoxidation. ${ }^{\mathbf{9 6}}$

Incorporation of various functional groups at the PANI aromatic ring shifts the potential $(E)$ of redox transitions in the high molecular mass compound. ${ }^{63,65,67,70}$ The value of $E$ is an important parameter for comparison of PANI derivatives and for estimating the electrophysical characteristics of compounds. The effect of substituents on the redox behavior of PANI derivatives is determined by the nature of the functional group and by its effect, i.e., electronic or steric.

Alkyl and alkoxy substituents are the most common electrondonating groups. Incorporation of these substituents into a macromolecule increases the potential of the first redox transition in the polymer..$^{20,21,41,47,48,63,65,67,70,74}$ These shifts in PANI alkyl derivatives can be explained taking into account the structure and conformational changes caused by the presence of substituents. It is known that the electronic properties of aromatic macromolecular systems are determined by changes in the torsion angle (dihedral angle) between the adjacent rings

a



$$
-2 \mathrm{e}^{-} \mid \uparrow+2 \mathrm{e}^{-}
$$

b
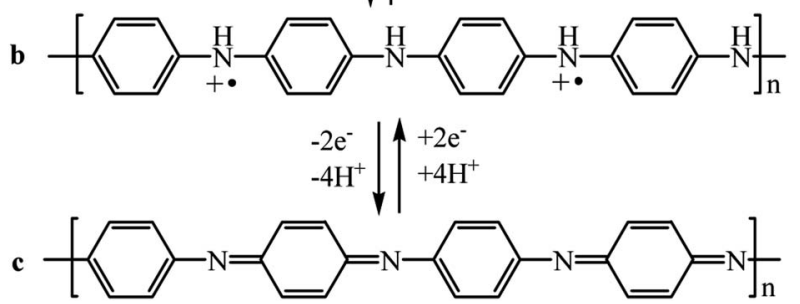

Scheme 1 PANI redox transitions: (a) leucoemeraldine, (b) emeraldine salt, (c) pernigraniline ( $\mathrm{R}=-\mathrm{H},-\mathrm{CH}_{3},-\mathrm{C}_{5} \mathrm{H}_{9}$, etc.).

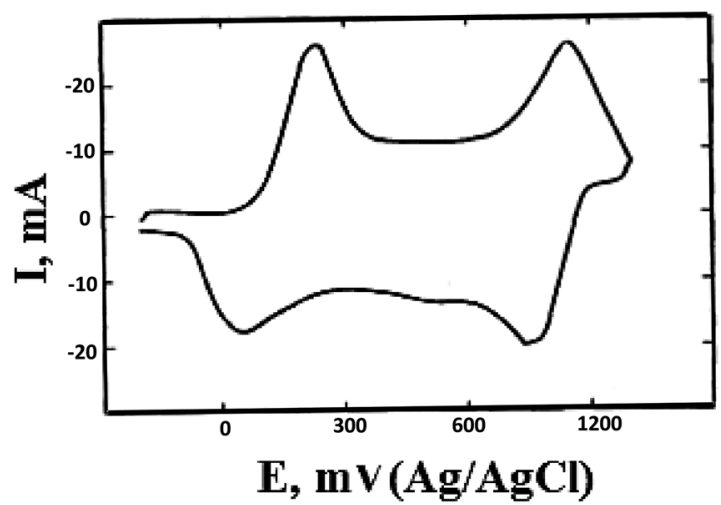

Fig. 1 A cyclic voltammogram of PANI (versus $\mathrm{Ag} / \mathrm{AgCl}$ ) in acidified aqueous solution.

in a polymer chain. The presence of a substituent decreases the degree of conjugation by increasing the torsion angle due to a bulky alkyl group and hence decreases the degree of orbital overlapping between the $\pi$-electrons of the aromatic ring and the unshared electron pair on the nitrogen atom. Incorporation of a substituent increases the energy of the radical cation of the semi-oxidized form of PANI (Scheme 1b), which hinders its formation from the completely reduced polyamine (Scheme 1a), i.e., increases the oxidation potential of the leucoemeraldine form.

At the same time, it may be assumed that the electrondonating effect of an alkyl group would stabilize the radical cation and thus decrease the oxidation potential. However, steric effects prevail over electron effects. The formation of the radical cation of a PANI derivative results in a lower $E_{1 / 2}$ for the second redox process (compared to unsubstituted PANI). The oxidation to the non-protonated quinonediimine form occurs more readily due to the formation of two completely $\mathrm{sp}^{2}$ hybridized nitrogen atoms, which decreases the steric hindrance due to a change in the bond angles at these atoms. $^{63,65}$

As the length of the alkyl group at an aniline ortho position increases, the oxidation potential decreases, which is consistent with the spatial rather than electronic effect of the electrondonating group.

Unlike alkyl groups, alkoxy substituents have a more appreciable electronic effect on the electrochemical properties of PANI derivatives and decrease their oxidation potential. ${ }^{\mathbf{6 3 , 6 5 , 6 7 , 7 0}}$ For example, polymethoxyaniline has a flatter conformation and therefore a lower oxidation potential. It is interesting that the oxidation potential of an ortho-methoxyaniline isomer, viz., 2-aminobenzylalcohol, is much higher. ${ }^{63}$ In the former case, the substituent is bound through an oxygen atom, and in the latter case, through a carbon atom. As a result, $-\mathrm{CH}_{2} \mathrm{OH}$ causes an electron-withdrawing effect whereas $-\mathrm{OCH}_{3}$ causes an electron-donating effect. Based on the above, it should be believed that electron-donating groups have a pronounced beneficial effect on the electrophysical characteristics of the polymer. 
Incorporation of more than one functional group at the aniline's aromatic ring decreases the oxidation potential in comparison with monosubstituted derivatives. It should also be noted that the presence of two methoxy groups at the aromatic ring decreases the oxidation potential relative to dialkylsubstituted or alkyl-alkoxy-substituted products. The lower potential of the first redox transition is explained by the strong electron-donating properties of the alkoxy group and formation of a planar structure. Replacement of one alkoxy group with a methyl group increases the oxidation potential due to an increase in the torsion angle, whereas replacement of two $-\mathrm{OCH}_{3}$ groups with two $-\mathrm{CH}_{3}$ groups gives a more twisted polymer, as confirmed by an increase in the oxidation potential. The presence of two alkoxy groups also affects the polymerization rate: it decreases with an increase in the substituent chain length. In view of the above, extension of the carbon chain in the alkoxy group should reduce the oxidation potential, nevertheless it gradually increases. This is apparently due to an increase in the steric effect.

Considerable shifts of the redox peaks were also noted for polyanthranilic acid. These are due to the different stabilization of the radical cations formed during the polymerization. ${ }^{80}$ Two oxidation peaks appear at 0.12 and $0.65 \mathrm{~V}$ versus $\mathrm{Ag} / \mathrm{AgCl}$. They correspond to the transitions from leucoemeraldine to emeraldine and from emeraldine to the perigraniline state of polyanthranilic acid, respectively. The redox nature of polyanthranilic acid was compared with that of PANI. It was noted that the peak caused by the second redox process had a higher potential than that observed in the case of PANI $(E=$ $0.23 \mathrm{~V}$ versus $\mathrm{Ag} / \mathrm{AgCl})$. It should be borne in mind that bulky substituents $(-\mathrm{COOH})$ at the aromatic ring cause stronger twisting and hence decrease the degree of chain conjugation. The latter adversely affects the stability of the polysemiquinone radical cations formed in the first redox process. Since the radical cation of polyanthranilic acid polysemiquinone is less stable in comparison with that of PANI, a higher potential is required for its formation. The potential of the second redox peak of polyanthranilic acid is smaller than that of PANI $(E=$ $0.79 \mathrm{~V}$ versus $\mathrm{Ag} / \mathrm{AgCl}$ ) in $0.5 \mathrm{~N} \mathrm{H}_{2} \mathrm{SO}_{4} \cdot{ }^{80}$ Hence, the oxidation of polysemiquinone with simultaneous deprotonation occurs more readily in polyanthranilic acid than in PANI. Like in the case of alkyl substituents, an increase in the bond angle at the nitrogen atom decreases the steric strain. ${ }^{\mathbf{8 0}}$

It is significant that the oxidation potentials of all substituted PANI derivatives are smaller than that of unsubstituted PANI, which indicates that PANI derivatives are oxidized more readily (Table 1 ).

Comparative analysis of the effect of electron-donating and electron-withdrawing groups in high molecular weight aniline (Table 1) on the oxidation potential has shown that the latter increases in the series: poly-2-fluoroaniline $<$ poly-2chloroaniline < polymethylaniline < PANI. ${ }^{\mathbf{9 8}}$ Thus, electronwithdrawing substituents that decrease the electron density on the nitrogen atom favor a decrease in the oxidation potential.

\subsection{Electrochemical stability}

Examination of the PANI structure allows it to be stated that it can exist in numerous states. ${ }^{99}$ Immersion of PANI in an electrolyte solution causes a change in its redox state depending on the applied potential, and this change is reversible. ${ }^{96}$ According to E. M. Genies and P. Noel, ${ }^{100}$ this behavior is also observed in PANI derivatives.

Incorporation of functional groups at the monomer's aromatic ring favorably affects the polymer stability. New PANI derivatives with higher electrochemical stability in comparison with the unsubstituted polymer were suggested. ${ }^{\mathbf{1 0 0}}$ For example, the presence of a hexyl substituent at the PANI aromatic ring increases the redox stability in electrochemical processes relative to unsubstituted PANI: ${ }^{8}$ ortho-propylaniline and ortho-hexylaniline lost only $10 \%$ of their active charge capacity after 160 cycles between -0.15 and $+0.4 \mathrm{~V}$ (versus $\mathrm{Cu} / \mathrm{CuF}$ ) in the environment of $\mathrm{NH}_{4} \mathrm{~F} \times 2.35 \mathrm{HF}$. The presence of an electrondonating substituent in the macromolecular chain inhibits the polymer overoxidation and hydrolysis processes. ${ }^{96}$

If the substituent simultaneously plays the role of a doping agent, the stability of PANI derivatives increases relative to the unsubstituted polymer. The voltammograms of the poly-orthosulfoaniline film obtained in $1 \mathrm{M} \mathrm{HCl}$ remain almost unchanged after 48 hour scanning in the range between 0.0 and $0.6 \mathrm{~V}$ at $50 \mathrm{mV} \mathrm{s}^{-1}$ (approximately 5000 cycles). ${ }^{94}$

Increasing the PANI charge capacity and stability is aimed at expanding its application in energy storage devices. Compounds with disulfide bonds seem to be promising materials in this field (Fig. 2). ${ }^{\mathbf{1 0 1}}$

In the case of PANI, incorporation of these bonds results in a energy capacity increase due to the intramolecular selfcatalysis between the PANI macromolecular chain (doping/ dedoping of the $\pi$-conjugated system) and disulfide bonds in the framing groups (breakdown/formation of S-S bonds). Since the oxidation-reduction of conductive PANI and disulfide bonds occurs in an identical potential range, the Li/poly[bis(2aminophenyloxy)disulfide] test cell displays a cathode charge capacity of $230 \mathrm{~mA} \mathrm{~kg} \mathrm{~g}^{-1}$ and an energy density of $460 \mathrm{~mW} \mathrm{~h}$ $\mathrm{kg}^{-1}$ on the cathode, which is about 2 times higher than the parameters of inorganic intercalation compounds. ${ }^{\mathbf{1 0 1}}$

In order to increase the PANI capacity, a ferrocenecontaining substituent is incorporated in its side chain (Scheme 2). ${ }^{\mathbf{1 0 2}}$ Charge/discharge tests demonstrated that the PANI derivative in question showed an elevated cycling stability relative to the unsubstituted analogue even after 30 cycles.

The electrochemical properties of a poly-ortho-methoxyaniline film were studied in an ionic liquid electrolyte. ${ }^{103}$ The experiment showed that the polymer has a high specific capacity of $260 \mathrm{~F} \mathrm{~g}^{-1}$ for $80 \%$ 1-butyl-3-methylimidazolyl tetrafluoroborate (liquid electrolyte) in polyethylene glycol and good electrochemical stability for a period of 3000 cycles. The specific energy shows a $70 \%$ retention from the initial value, and the specific power remains extremely stable throughout the entire cycling period. According to literature, this is the first report on the study of polymer films in an ionic liquid and in a polyethylene glycol electrolyte. ${ }^{\mathbf{1 0 3}}$ 
Table 1 Oxidation potential of polyaniline derivatives

\begin{tabular}{llllr}
\hline Polymer & $E_{\text {ox }}, \mathrm{V}$ & Ref. & Polymer & $E_{\text {ox }}, \mathrm{V}$ \\
\hline PANI & 0.12 & 63 & Poly-ortho-methylaniline & 0.20 \\
Poly-2-methoxyaniline & 0.08 & 63 & Poly-2-aminobenzyl alcohol & 63 \\
Poly-ortho-ethylaniline & 0.30 & 67 & Poly-2-ethoxyaniline & 63 \\
Poly-ortho-propylaniline & 0.15 & 95 & Poly-2-methoxy-5-methylaniline & 6.22 \\
Poly-ortho-hexylaniline & 0.20 & 95 & Poly-2-hexyloxyaniline & 0.12 \\
Poly-2,5-dimethylaniline & 0.24 & 63 & Poly-2,5-dihexyloxyaniline & 0.16 \\
Poly-ortho-butoxyaniline & 0.09 & 65 & Poly-2,5-dimethoxyaniline & 0.09 \\
Poly-ortho-fluoroaniline & 0.52 & 98 & Poly-2,5-dibutoxyaniline & 65 \\
Poly-ortho-chloroaniline & 0.29 & 113 & Polyanthranilic acid & 65 \\
Poly[bis(2-aminophenyloxy)disulfide] & 0.32 & 101 & Poly-[6-(2-aminophenol-9H-yl)-hexylferrocene carboxylate] & 0.09 \\
& & & &
\end{tabular}

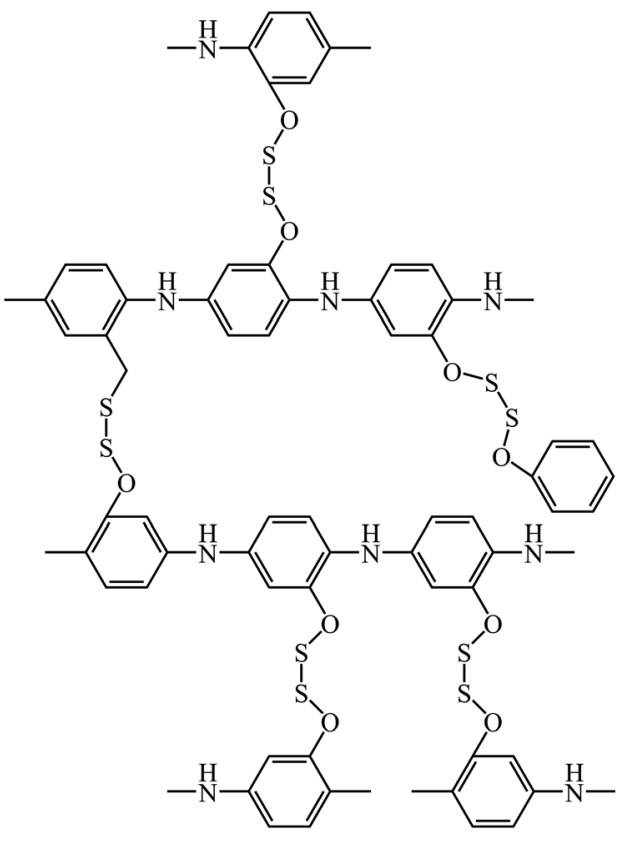

Fig. 2 Poly[bis(2-aminophenyloxy)disulfide.

\subsection{Conductivity}

PANI is among the most prominent representatives of electrically conductive polymers. It has a controlled electronic conductivity in the range of $10^{-10}$ to $10^{1} \mathrm{~S} \mathrm{~cm}^{-1}$ as well as ionic conductivity.
The PANI chain is a regular sequence of monomeric units providing conjugation of the $\pi$-electron clouds on the aromatic ring and the unshared electron pair on the nitrogen atom, which overlap above and below the plane of the polymer chain. ${ }^{104,105}$ The conjugated system of the macromolecular compound determines the level of charge carrier mobility. The conductivity of PANI depends on the content and mobility of positive polarons (radical cations on nitrogen atoms, charge carriers) in it that are formed during oxidation (Scheme 3). In fact, leucoemeraldine contains no oxidized nitrogen atoms, therefore its conductivity is low, $10^{-8}$ to $10^{-10} \mathrm{~S} \mathrm{~cm}^{-1} \cdot{ }^{109}$ During oxidation and with an increase in the number of charge carriers, the electrical conductivity increases. Emeraldine, a stable semioxidized form of PANI, has high conductivity $\left(10-100 \mathrm{~S} \mathrm{~cm}^{-1}\right)$.

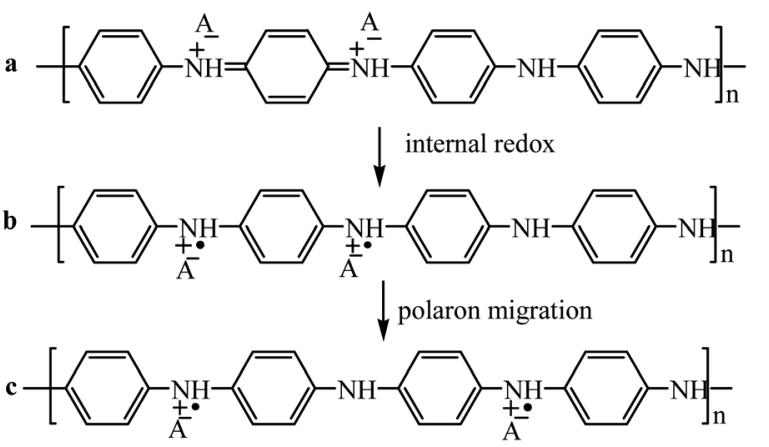

Scheme 3 PANI structure: (a) bipolaron (dication); (b and c) polaron (cation radical). ${ }^{106}$

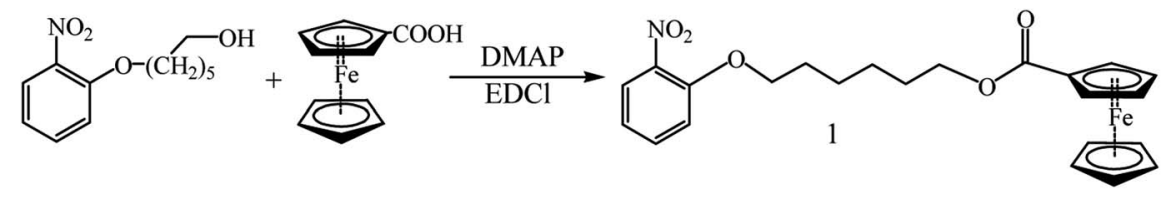

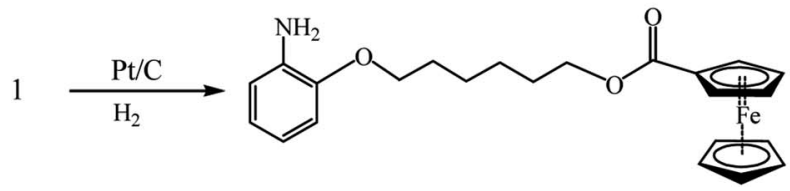

Scheme 2 Scheme of synthesizing 6-(2-aminophenol-9H-yl)-hexylferrocenecarboxylate. ${ }^{88}$ 
Further oxidation of PANI results in a decrease in electrical conductivity, while pernigraniline, the completely oxidized form, is even a dielectric $\left(10^{-10} \mathrm{~S} \mathrm{~cm}^{-1}\right)$.

The effect of substituents on the electronic conductivity of PANI depends on their nature. The presence of both electrondonating and electron-withdrawing groups in the macromolecule results in a decrease in electrical conductivity, but it is caused by different reasons.

The electrical conductivity of doped forms of PANI derivatives with electron-donating substituents (poly-ortho-toluidine, poly-ortho-ethylaniline, poly-ortho-propylaniline) is higher than that of their undoped forms but lower than that of PANI. The decrease in conductivity was explained ${ }^{\mathbf{6 3 , 6 5}}$ by the fact that incorporation of a methyl group at the benzene ring increases the torsion angle between the conjugated rings and thereby reduces the steric strain with increasing distance between the polymer units. The decrease in conductivity also depends on the size of the functional group that is present. The longer and bulkier the substituent in the side chain, the greater the steric effect is and the less accessible is the nitrogen atom for the doping agent that is a charge carrier, and hence, the higher is the shielding effect of the group. ${ }^{\mathbf{1 0 2}}$ Experimental data show (Table 2) that the steric effects that are due to the increase in the dihedral angle upon incorporation of alkyl substituents prevail over the electronic effects. The results are consistent with the measurements of the conductivity of PANI and alkyl substituted derivatives: it was found that the conductivity decreases in the series PANI > poly-ortho-toluidine > poly-ortho-ethylaniline > poly-ortho-propylaniline. ${ }^{63,65}$

The presence of an oxygen-containing electron-donating group at the ortho position of aniline, like with alkyl groups, results in a decrease in electrical conductivity. However, despite the narrowing of the band gap in poly-ortho-methoxyaniline, the conductivity of this material is significantly lower than that of alkyl derivatives which, in turn, widen the band gap. Apparently, this can be explained by the electronic effect of alkoxy groups on the properties of the polymer. It was noted ${ }^{67}$ that the electrical conductivity of poly-ortho-methoxyaniline is higher than that of its isomer, poly-2-aminobenzylalcohol. The larger volume of the $-\mathrm{CH}_{2} \mathrm{OH}$ group in comparison with $-\mathrm{OCH}_{3}$ results in a more twisted polymer with a low degree of conjugation and low conductivity. Based on this information, it was assumed that an atom with a low van der Waals radius (e.g., oxygen) favors the formation of a polymer with good electrical properties. ${ }^{67,70}$

An increase in the number of substituents at the aromatic ring of aniline leads to a larger torsion angle relative to monosubstituted derivatives, which causes a decrease in electrical conductivity. ${ }^{65}$ In fact, the lateral bond relieves the strain, and more regular polymer structures are formed. Bulky substituents (alkyl groups) induce additional deformation along the macromolecular chain. The latter favors a decrease in the degree of conjugation and hence a decrease in conductivity (for example, poly-(2,5-dimethylaniline)). Substituted poly-2,5-alkoxyanilines have a lower band gap and higher electrical conductivity in comparison with alkyl derivatives. However, replacement of an alkoxy group at position 5 of the aromatic ring with an alkyl group results in a sharp conductivity decrease due to an increase in the torque angle of the polymer main chain caused by the steric effect of the alkyl substituent. In comparison with PANI, poly-2,5-dialkoxyaniline has a lower oxidation potential, possibly due to an increase in the distance between the chains. Elongation of the carbon chain in dialkoxy derivatives of PANI decreases the conductivity. In the case of short substituents $\left(-\mathrm{OCH}_{3},-\mathrm{OC}_{2} \mathrm{H}_{5}\right)$, the presence of a second alkoxy group at position 5 gives materials with improved conductivity owing to the formation of a more regular structure ${ }^{65}$ However, this is not observed in disubstituted polymers with long side chains, since the interchain distance increases in this case.

As mentioned above, elongation of the chain of a substituent at the aromatic ring decreases the electrical conductivity.

Table 2 Conductivity of polyaniline derivatives

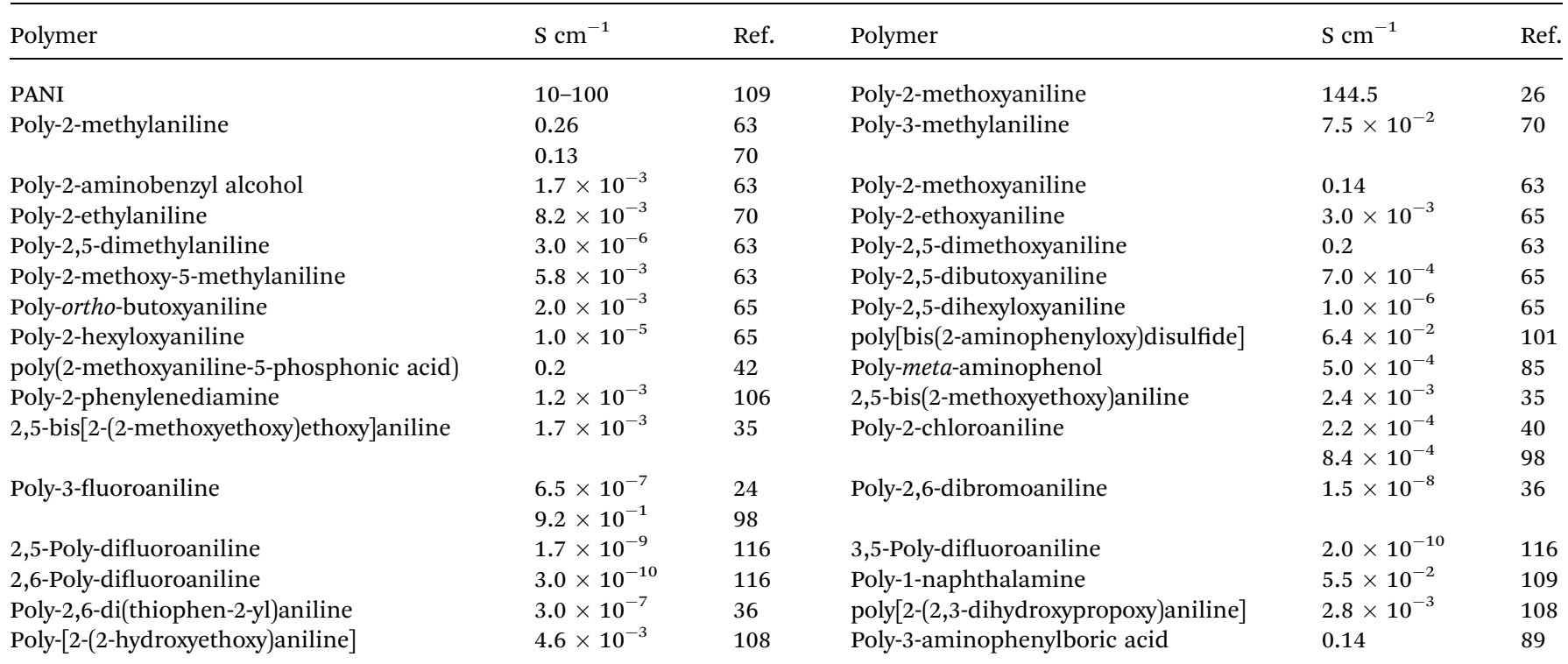


Nevertheless, no noticeable dependence of electrical conductivity of polymers upon elongation of substituents was observed (Fig. 3), and the electrical conductivity of these materials was (1.7-2.4) $\times 10^{-3} \mathrm{~S} \mathrm{~cm}^{-1} \cdot{ }^{83}$ Incorporation of one or two additional hydroxy groups in PANI functionalized with an alkoxy group causes a conductivity decrease in comparison with PANI due to a planarity violation in the macromolecular chain structure. ${ }^{107}$

The great importance of the PANI's planar structure is confirmed by the fact that its well studied derivative, poly-1naphthylamine (Scheme 4), is characterized by a flat structure of the macromolecular chain and its conductivity reaches 0.055-0.083 $\mathrm{S} \mathrm{cm}^{-1}{ }^{108}$

Incorporation of an amino or hydroxy group at the aromatic ring of PANI changes the polymer structure. ${ }^{\mathbf{8 6 , 1 1 0 , 1 1 1}}$ According to these studies, poly-meta-aminophenol and poly-ortho-phenylenediamine form ladder-type structures with open and closed rings (Fig. 4). The properties of the compounds differ: polymers with open ring structure have higher solubility and the following conductivity in doped state: poly-meta-aminophenol, $1.0 \times 10^{-7} \mathrm{~S} \mathrm{~cm}{ }^{-1}$; poly-ortho-phenylenediamine, $1.2 \times$ $10^{-3} \mathrm{~S} \mathrm{~cm}^{-1}$.

Since the electron-donating effect of alkyl groups adversely affects the conductivity of PANI, it had to be expected that an electron-withdrawing substituent would increase it. However, the electrical conductivity of poly-ortho-chloroaniline, which is the highest among halogen derivatives, ${ }^{\mathbf{2 4 , 8 4 , 8 5 , 1 1 2}}$ is significantly lower than that of its ortho-alkyl-substituted analogues. $^{\mathbf{4 0 , 8 4 , 9 8 , 1 1 3 , 1 1 4}}$ This result confirms the fact that the decrease in conductivity upon incorporation of alkyl groups is to a greater extent due to the steric effect than to the electronic one. The low electrical conductivity of the PANI halo-derivatives may result from a decrease in intramolecular charge diffusion due to electron-withdrawing side groups and variation in the structure planarity. ${ }^{24}$

The electrical conductivity of monosubstituted halogenated polymers is higher than that of PANI dihalo-derivatives. ${ }^{\mathbf{1 1 5 , 1 1 6}}$ An important role belongs to the halogen electronegativity: the electrical conductivity decreases with its increase in the series of halogen-containing PANI derivatives. ${ }^{\mathbf{8 3 , 1 1 2 , 1 1 5}}$ In the case of polydihaloanilines, a low doping level is observed due to the electron-withdrawing effect of substituents leading to a decrease in the basicity of nitrogen atoms. Under these conditions, the doping possibilities are minimal, hence a low conductivity is observed. ${ }^{\mathbf{1 1 5}}$ Of the PANI derivatives with

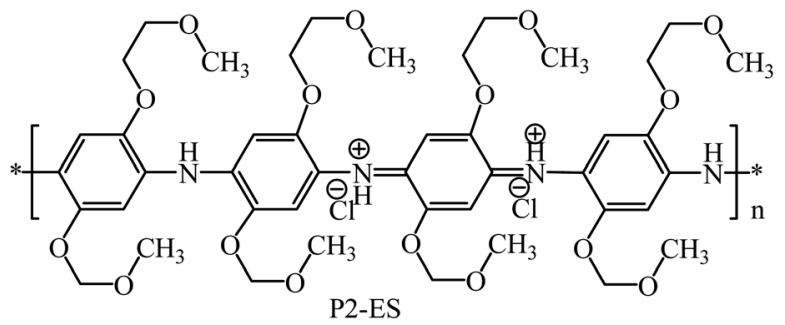

Fig. 3 Poly-2,5-bis(2-methoxyethoxy)aniline. ${ }^{24}$

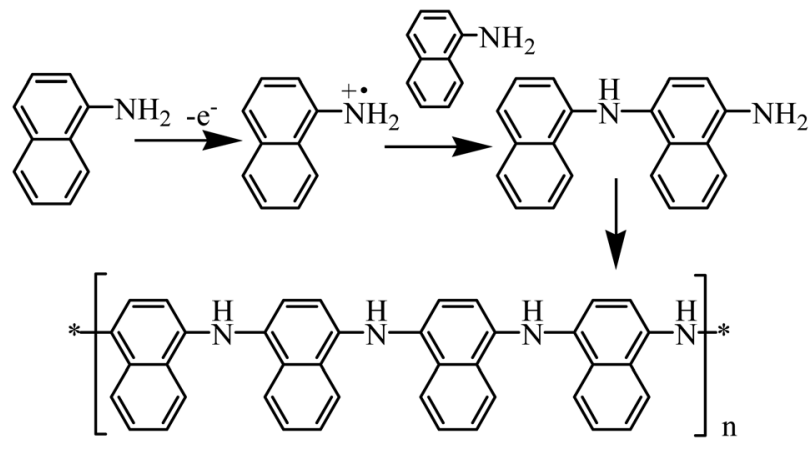

Scheme 4 Poly-1-naphthylamine.

substituents at positions 3,5-, 2,6- and 2,5- studied by Rubio et al. ${ }^{116}$ the latter shows the best conductivity (Fig. 5). Since halogens at positions 2,5- and 2,6- affect the basicity of the nitrogen atom more strongly, the level of doping and hence the conductivity of this sample is the largest.

Studies on the synthesis of various PANI derivatives with heteroatom-containing substituents ${ }^{\mathbf{4 9 , 1 0 0 , 1 0 1}}$ are rather interesting. For example, a number of disubstituted PANI derivatives were obtained ${ }^{62}$ in order to study the structure-property (solubility and conductivity) relationships (Fig. 6). It was found that with an increase in the volume of substituents framing the macromolecule, the electrical conductivity decreased from the methoxy group at position 2,6- or 3,5- to 2,6-dithiophen-2-yl and 2,6-dibromopolyaniline. ${ }^{62}$

As a rule, heteroatom-containing substituents are intentionally incorporated in PANI in order to change some specific properties of the final material and to expand the spectrum of possible applications in a particular industry. ${ }^{37,101,102}$ In order to increase the charge capacity of PANI, we obtained a polymer with disulfide bridges, i.e., poly[bis(2-aminophenyloxy) disulfide], whose electrical conductivity is 2-3 orders of magnitude lower than that of PANI $-6.4 \times 10^{-2} \mathrm{~S} \mathrm{~cm}^{-1}$ (Fig. 7). ${ }^{102}$

An increase in the capacity of a material is also achieved in the case of a synthesized ferrocene-containing polymer (Scheme 2) with an electrical conductivity of $2.1 \times 10^{-6} \mathrm{~S} \mathrm{~cm}^{-1} \cdot{ }^{102}$ In this case, the decrease in electrical conductivity is due to the presence of bulky substituents with a large steric substituent effect, which disrupts the conjugated structure of the polymer chain



Fig. 4 Structure of poly-meta-aminophenol with closed ring (a) and open ring (b). 
<smiles>[R]c1cc(Nc2c([R])cc([NH3+])cc2[R])cc([R])c1C</smiles><smiles>[Y]c1cc([R])c(Nc2cc([R])c([NH3+])c([R])c2)c([R])c1</smiles><smiles>[Y]c1cc([R])c(Nc2cc([R])c([NH3+])cc2[R])cc1[R]</smiles>

Fig. 5 Substituted PANI: 3,5- (a), 2,6- (b), 2,5- (c).

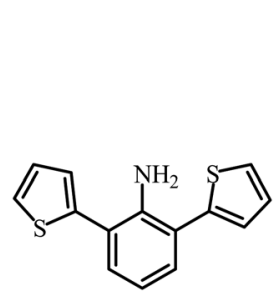

a

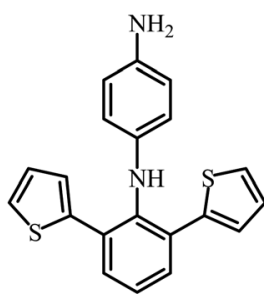

b
Fig. 6 Structures of 2,6-di(thiophen-2-yl)aniline (a) and N1-(2,6di(thiophenyl-2-yl)phenyl)benzene-1,4-diamine (b).<smiles>Nc1ccccc1OSSOc1ccccc1N</smiles>

Fig. 7 2-Aminophenyloxydisulfide monomer. ${ }^{100}$

and reduces the electron transfer along the macromolecule. This induced chain twisting not only increases the energy barrier of charge transfer but also reduces the charge delocalization along the chain. ${ }^{101}$

A synthesis of a PANI containing a substituent with liquid crystal properties in the side chain was reported. ${ }^{37}$ The sample in undoped state had a conductivity of $10^{-11} \mathrm{~S} \mathrm{~cm}^{-1}$. In a magnetic field, the side substituents changed orientation and became strictly perpendicular to the main polymer chain. As a result, the conductivity increased to $10^{-6} \mathrm{~S} \mathrm{~cm}^{-1}$ (Fig. 8). The change in electrical conductivity by 5 orders of magnitude can be attributed to the alignment of the polymer chain and a significant increase in the conjuration length.

Incorporation of dopants is an efficient way for modifying PANI. Bearing in mind that the counterion readily leaves the polymer under the effect of external factors, it is important that substituents causing a self-doping effect be present in the aromatic ring of the macromolecular chain. A large number of studies dealt with this urgent problem, that is, synthesizing

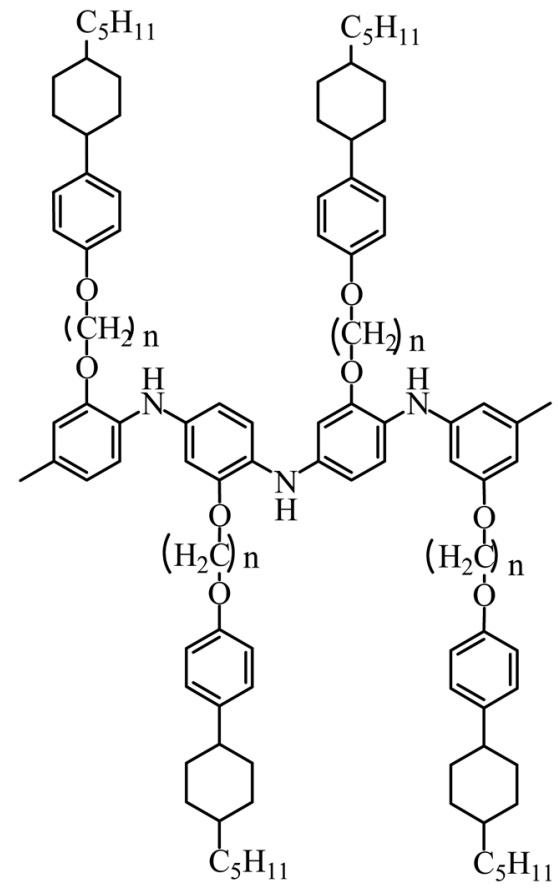

Fig. 8 Scheme of orientation of polymer side chains under external magnetic field. ${ }^{37}$

substituted PANI with a self-doped polymer system. ${ }^{42-44,75,76}$ However, the electrical conductivity of these materials is low. The experimental electrical conductivity values of the acid sample obtained in ref. 44 are about $10^{-9} \mathrm{~S} \mathrm{~cm}^{-1}$. These low values should be attributed to the presence of a strong electronwithdrawing group in the functionalized PANI macromolecule, which simultaneously reduces the electron density on the nitrogen atom and the degree of polymerization. ${ }^{43,44,75}$ To compensate the effects of the electron-withdrawing substituent, an electron-donating group was incorporated at the ortho position of the aromatic ring (Fig. 9). As a result, a water-soluble polymer with enhanced electrical conductivity $\left(0.02 \mathrm{~S} \mathrm{~cm}^{-1}\right)$ was obtained..$^{43,44,75}$

The first successful synthesis of a self-doped PANI was carried out by Epstein. ${ }^{117}$ As expected, sulfonation of PANI significantly improved its solubility ${ }^{118-121}$ and beneficially affected the conductive properties. ${ }^{122}$ The electrical conductivity of PANI sulfonic acid derivatives depends on the sulfur: nitrogen ratio. It determines the degree of doping of a high molecular mass compound, which affects the number of polarons, i.e., charge carriers in the polymer. As the $\mathrm{S}: \mathrm{N}$ ratio increases, the solubility improves noticeably, while the

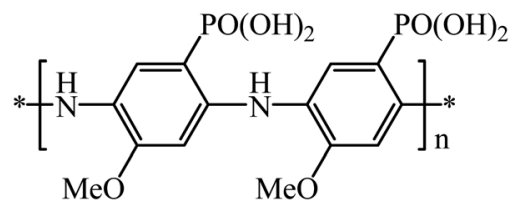

Fig. 9 Poly-2-methoxyaniline-5-phosphoric acid. 
electrical conductivity of the sample decreases from 0.023 to 1.7 $\times 10^{-5} \mathrm{~S} \mathrm{~cm}^{-1}$. $^{\mathbf{6}-88}$

It was found in a study of the behavior of self-doped poly-3aminophenylboric acid (Fig. 10) over a wide $\mathrm{pH}$ range $\mathrm{e}^{89}$ that the tetrahedral boron atom is stable during potential cycling and thus it increases the polymer's electroactivity. Its conductivity reaches a maximum in an intermediate state between the fully reduced form, leucoemeraldine, and the fully oxidized form, pernigraniline. As the $\mathrm{pH}$ increases from 1 to 8 , the electrical conductivity of poly-3-aminophenylboric acid changes from 0.14 to $0.03 \mathrm{~S} \mathrm{~cm}^{-1}$ (potential range $0.1-0.4 \mathrm{~V}$ ). Non-modified PANI shows a decrease in the maximum conductivity by almost 2 orders of magnitude at $\mathrm{pH}$ values from 0 to $4 .^{89}$

Thus, the main factors affecting the conductivity of PANI derivatives are the parameters determining the nature of the substituent, viz., electron-donating and electron-withdrawing properties, as well as the volume of the functional group. The effect of environment $\mathrm{pH}$ on the properties of PANI derivatives whose aromatic rings contain orientants of the first or second kind is also important. ${ }^{\mathbf{1 1 5 , 1 1 6 , 1 2 3}}$ Acids better protonate derivatives with an electron-donating group, as confirmed by UV spectroscopy and electrical conductivity data. Upon incorporation of electron-withdrawing substituents as the macromolecule framing groups, the basicity of the nitrogen atom decreases and protonation of PANI derivatives only occurs in highly acidic media. ${ }^{115,116}$ Moreover, protonation with bulkier acids occurs more easily. ${ }^{123}$ It is interesting that the dependence of the electrical conductivity on the acid concentration used in the synthesis is nonlinear. Electrical conductivity first increases with an increase in acid concentration, but only to a certain point. A further increase in the medium acidity results in a conductivity decrease due to possible substitution at the aromatic ring. ${ }^{26}$

The history of the electrically conductive material, i.e., the choice of an appropriate method for the polymer synthesis and oxidizing agents, also plays a role in achieving high electrical conductivity. In fact, the conductivity of halo-containing PANI samples was found to depend on whether potassium dichromate is used in its synthesis: the conductivity decreases in this case. ${ }^{\mathbf{1 1 5 , 1 1 6}}$ The degree of polymer crystallinity determined by the synthesis technique also affects the conductivity of functionalized PANI samples. As it was noted, ${ }^{21}$ the highest degree of crystallinity, and hence the maximum electrical conductivity of PANI derivatives, are reached when they are obtained by interface polymerization. Table 2 shows the electrical conductivity values of PANI derivatives, which can be used to track the dependence of the polymer properties on its structure.

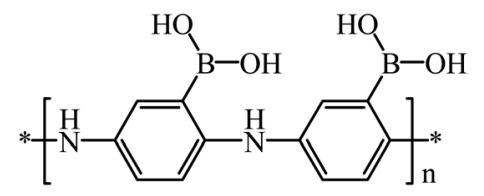

Fig. 10 Poly-3-aminophenylboric acid.

\subsection{Optical properties}

Comparative studies of the electronic spectra of unsubstituted PANI and its derivatives provide an understanding of the molecular geometry changes caused by the effect of substituents on the main polymer chain.

The PANI absorption spectrum is characterized by two absorption maxima at 330 and $620 \mathrm{~nm}$. The first one corresponds to the $\pi-\pi *$ electron transition between the adjacent conjugated aromatic rings in the polymer chain. The second absorption maximum at longer wavelengths is due to the $n-\pi^{*}$ electronic transition in the PANI's quinoid moiety. The areas under these peaks correspond to the number of benzoid and quinoid moieties in the polymer. Therefore, it is possible to determine the ratio of oxidized and non-oxidized moieties in the macromolecular chain.

The electronic spectra of PANI derivatives also consist of two absorption bands. ${ }^{47,48,65,67,70,79}$ Nevertheless, when various substituents are incorporated at the PANI's aromatic ring, a shift in the absorption maxima relative to the unsubstituted polymer is observed due to electronic and steric effects from the polymer's framing groups. ${ }^{69}$

It is noted in literature sources ${ }^{64-66,70}$ that alkyl groups at the ortho position result in a hypsochromic shift of the PANI's absorption maxima, while alkoxy groups cause a bathochromic shift. This fact indicates that electron-donating groups have various effects on the properties of PANI. The tetrahedral carbon atom of the alkyl group increases the torsion angle of the polymer chain and a non-planar polymer structure is formed. For this reason, the hypsochromic shift in polyalkylanilines is due to the steric factor (Fig. 11).

At the same time, alkoxy groups bound to the aromatic ring through an oxygen atom lead to smaller deformation of the planar conformation of the PANI derivative. ${ }^{67}$ It is believed ${ }^{65}$ that in the latter case, a more planar polymer structure is formed because the van der Waals radius of the oxygen atom in the methoxy group $(1.40 \AA)$ is smaller than that of the carbon atom in the methyl group $(2.00 \AA)$. Therefore, the bathochromic shift of the absorption maximum of polymethoxyaniline is most likely caused by the electronic effect of the alkoxy group. ${ }^{63,65,67} \mathrm{It}$

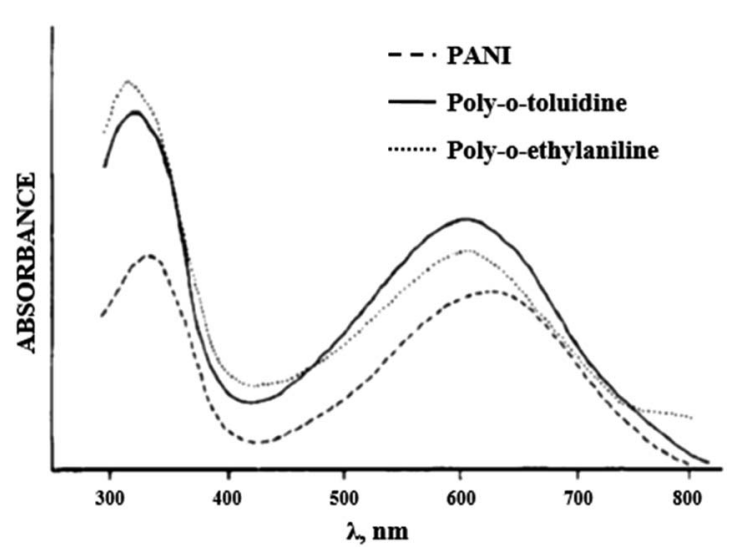

Fig. 11 Electronic absorption spectrum of PANI derivatives in DMF. Reproduced with permission from ref. 70 . 
was found later that incorporation of the second alkoxy group contributes to an even greater bathochromic shift of the absorption maximum. ${ }^{65}$ Upon elongation of the substituent's carbon chain, the bathochromic shift of the absorption peaks increases, which can be attributed to the strong electrondonating properties of alkoxy groups (Table 3).

An increase in the hypsochromic shift of the absorption maximum is observed for PANI alkyl derivatives with elongated side chains. ${ }^{47,48,67,78}$

PANI derivatives with electron-withdrawing substituents also exhibit a bathochromic and hypsochromic shift of absorption maxima. ${ }^{27,84,97}$ Halo derivatives of PANI have an absorption maximum with a bathochromic shift with respect to PANI that is due to the presence of an electron-withdrawing halogen substituent that decreases the delocalization of the electric charge in the conjugated polymer system (Fig. 12). ${ }^{98}$

With an increase in the electronegativity of the halogen substituent, the absorption peak shifts bathochromically. ${ }^{\mathbf{8 4}}$ However, a hypsochrome shift (315 $\mathrm{nm}$ ) was observed for PANI bromo and iodo derivatives (Fig. 13). Since the atomic radii of bromine and iodine are larger than that of chlorine, they significantly distort the planarity of PANI's high molecular structure, which results in a sharp decrease in the conjugation length along the main polymer chain. In this case, the steric effect of halogen substituents predominates over their electronic effect. It was noted that the hypsochromic shift increases with an increase in the bromine content in functionalized PANI. ${ }^{27}$

The absorption maxima of poly-ortho-phenylenediamine are shifted relative to those of PANI towards shorter wavelengths due to the steric effect of the functional group. ${ }^{85,109,110}$ The hypsochromic shift of the maxima in the spectra of poly-metaaminophenol and poly-ortho-phenylenediamine, despite the strong electron-donating effect, occurs because they exist in the form of a ladder-type structure, which decreases the degree of conjugation of the polymer chain, similarly to the majority of PANI derivatives.

In the previous sections, we considered PANI derivatives containing bulky heteroatom substituents. ${ }^{37,100,101}$ The electronic spectra of these derivatives show a hypsochromic shift of the absorption maxima due to the steric hindrance created by

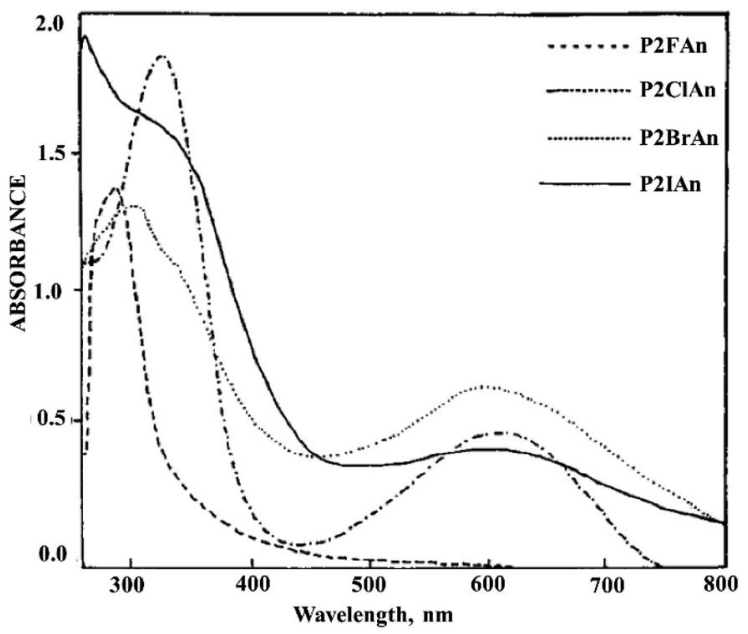

Fig. 12 Electronic spectrum of PANI derivatives in DMSO. Reproduced with permission from ref. 85 .

a substituent, which distorts the coplanarity of the $\pi$-system, thus reducing the degree of conjugation between the units. Moreover, for poly[bis(2-aminophenyloxy)disulfide], the intensity of the transition at $310 \mathrm{~nm}$ is much higher than that $551 \mathrm{~nm}$. In the case of unsubstituted PANI, the two transitions are characterized by approximately equal intensity. ${ }^{96}$ This is probably due to the low content of quinoneimine moieties in the polymer. For ferrocene-containing PANI, no absorption maximum of the imine form is observed in the electronic spectrum. ${ }^{102}$

As noted above, the UV spectra of PANI derivatives with charged groups in the side chain manifest in comparison with unsubstituted PANI caused by electronic and steric effects of the substituents. ${ }^{94}$ It can be expected that sulfonation of the aromatic ring in PANI would increase the twist angle between the adjacent rings in order to alleviate the steric strain. The hypsochromic shift of electronic transitions in sulfonated PANI is consistent with the decrease in the degree of conjugation due to an increase in the torsion angle of phenyl rings. The latter is caused by repulsion between bulky $-\mathrm{SO}_{3}$ groups and hydrogen atoms of adjacent aromatic rings. An increase in the content of

Table 3 Optical properties of polyaniline derivatives ${ }^{a}$

\begin{tabular}{lllll}
\hline Polymer & $\lambda_{1}, \mathrm{~nm}$ & Ref. & Polymer & $\lambda_{1}, \mathrm{~nm}$ \\
\hline PANI & 315 & 65 & Poly-2-methylaniline & 310 \\
Poly-2-aminobenzyl alcohol & 308 & 65 & Poly-2,5-dimethylaniline & 63 \\
Poly[( \pm -2-(cis-butyl)aniline] & 302 & 48 & Poly-2-fluoroaniline & 308 \\
Poly-meta-aminophenol & 250 & 84 & Poly-2-chloroaniline & 289 \\
Poly-[6-(2-aminophenol-9H-yl)-hexylferrocene carboxylate] & 320 & 102 & Poly-2-bromoaniline & 98 \\
Poly-2-methoxyaniline & 325 & 65 & Poly-2,5-dimethoxyaniline & 324 \\
Poly-2-ethoxyaniline & 320 & 65 & Poly-2,5-diethoxyaniline & 315 \\
Poly-2-butoxyaniline & 340 & 65 & Poly-2,5-dibutoxyaniline & 350 \\
Poly-2-hexyloxyaniline & 340 & 65 & Poly-2,5-dihexyloxyaniline & 65 \\
Poly-2,6-di(thiophen-2-yl)aniline & 250 & 36 & poly[bis(2-aminophenyloxy)disulfide] & 375
\end{tabular}

${ }^{a} \lambda_{1}$ is the wavelength of the first absorption maximum. 




Fig. 13 Absorption spectrum of PANI halogen derivatives. Reproduced with permission from ref. 98.

sulfonic acid groups in PANI initiates a hypsochromic shift of the absorption peaks characteristic of conjugated systems. ${ }^{86,87}$

The absorption spectrum is considerably affected by the concentration and nature of the doping agent, ${ }^{69,100,109,110} \mathrm{pH}$ of the medium, ${ }^{75,76}$ as well as the solvent used. ${ }^{47,48,79}$ When $\mathrm{HCl}$ is used as the doping agent for poly[bis(2-aminophenyloxy) disulfide], absorption in the region of $310 \mathrm{~nm}$ of the electronic spectrum does not change, whereas the band at about $551 \mathrm{~nm}$ disappears completely. Two new absorption bands appear at 426 and $865 \mathrm{~nm}$ (Fig. 14) due to the formation of polarons (cation radicals) based on quinoneimine units in the polymer.

It should be noted that the method of polymer synthesis does not noticeably affect the peak shifts. Polyanthranilic acid, one of PANI derivatives, was synthesized by two methods, namely, by interface polymerization and by the classical chemical method..$^{80}$ The UV spectra of the same high molecular mass product obtained by different techniques (Fig. 15) showed no differences, since the band gap remained almost the same (from 2.5 to $2.7 \mathrm{eV}$ ). ${ }^{80,124-126}$

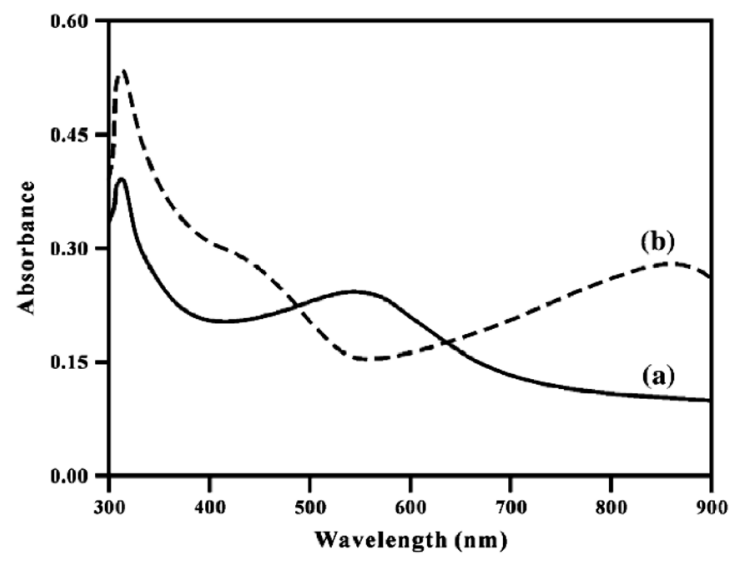

Fig. 14 Electronic spectrum of undoped (a) and doped (b) poly[bis(2aminophenyloxy)disulfide] in DMF. Reproduced with permission from ref. 101.
A study on the synthesis of poly-ortho-phenylenediamine in Brønsted acids with different strengths revealed interesting regularities. In particular, on transition from phosphoric to hydrochloric acid and then to sulfuric acid, i.e., as the acid strength increased, the absorption maximum in the electronic spectrum regularly shifted from a weak acid $\left(\mathrm{H}_{3} \mathrm{PO}_{4}\right)$ to a superacid $\left(\mathrm{H}_{2} \mathrm{SO}_{4}\right)$ by $5 \mathrm{~nm}$ to the bathochromic region with respect to the undoped state. ${ }^{110,111}$

The electronic spectra obtained for the doped polymer in solvents differing in polarity, chloroform and acetone, showed the following. ${ }^{47,48,79}$ In low polar chloroform, two electron transitions are observed at $260-300 \mathrm{~nm}$ and $530-600 \mathrm{~nm}$. The absorption maximum at $300 \mathrm{~nm}$ corresponds to the $\pi-\pi^{*}$ electron transition in the aromatic ring. Here we observe a bathochromic shift in comparison to $283 \mathrm{~nm}$ for PANI due to the presence of an alkyl substituent. The transition in the longer-wavelength region $(605 \mathrm{~nm})$ is due to the quinoid moiety ( $n-\pi^{*}$ electron transition). This absorption band is characteristic of the non-protonated quinoid or pernigraniline state. On passage to a polar solvent, acetone, the PANI derivative already manifests three absorption maxima: the first one at $208 \mathrm{~nm}$ corresponds to the $\pi-\pi *$ electron transition in the quinoid ring, while the second and third peaks at 333 and $511 \mathrm{~nm}$ demonstrate a behavior similar to the electron transitions with bathochromic shifts in the polymer recorded in a non-polar solvent. ${ }^{47,48,79}$

Using UV spectroscopy, it is quite realistic to determine the changes in the polymer state at various environment $\mathrm{pH}$ values. In fact, it was shown that poly-3-aminophenylboric acid was in conductive state up to $\mathrm{pH}=7 .^{89,90}$ A further increase in $\mathrm{pH}$ resulted in a hypsochromic shift of the absorption maxima and a decrease in the conductive properties of the polymer being tested (Fig. 16).

Obviously, the electronic spectra of PANI derivatives can characterize the nature of the effect of substituents on the properties of the resulting material. Substituents with a small

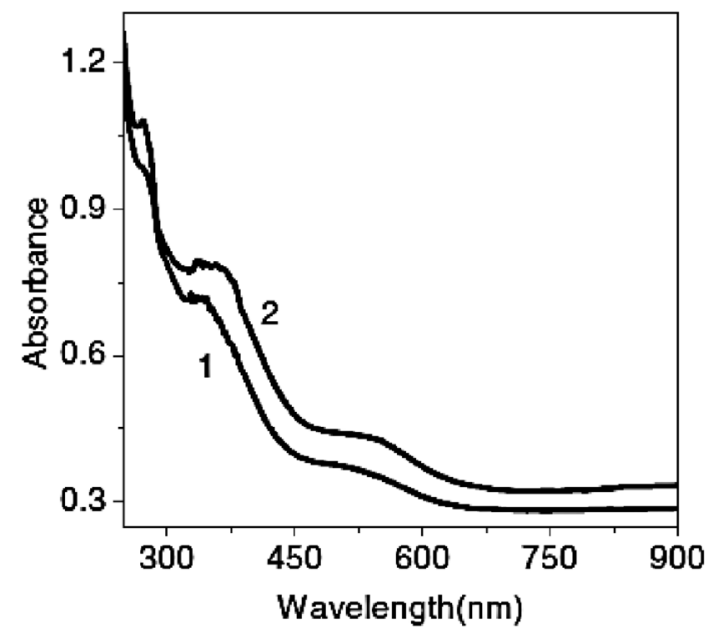

Fig. 15 Electronic spectra of polyanthranilic acid obtained by: 1 single-phase method; 2 - two-phase method in $0.5 \mathrm{~N} \mathrm{H}_{2} \mathrm{SO}_{4}$. Reproduced with permission from ref. 80 . 


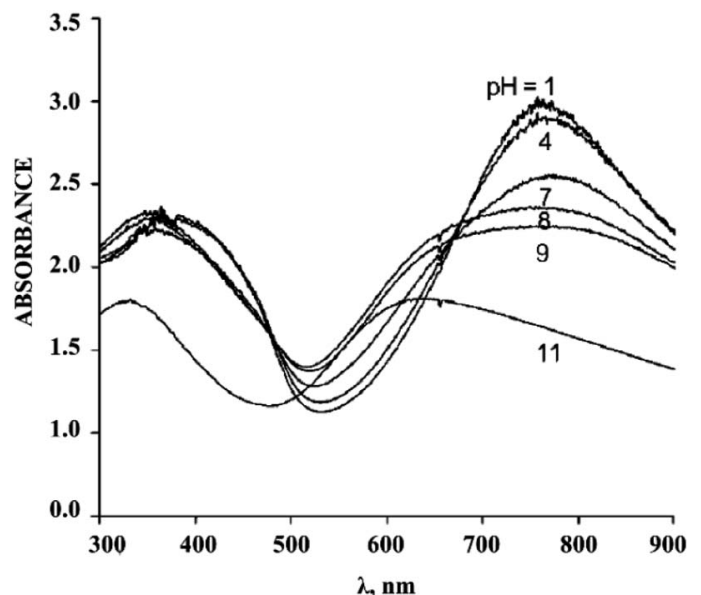

Fig. 16 Electronic spectrum of poly-3-aminophenylboric acid at various $\mathrm{pH}$ values. Reproduced with permission from ref. 89 .

atomic radius and flat configuration have a noticeable electronic effect that is characterized by a bathochromic shift of the absorption maxima. The electronic effect is primarily responsible for the solubility in basic aqueous solutions, the independence of the polymer conductivity on $\mathrm{pH}$, charge localization, and $\mathrm{pH}$-dependent potential of the first redox process. ${ }^{94}$ Due to the large atomic radii and molecular weights, bulky substituents present in a macromolecule contribute to an increase in the torsion angle between the aromatic rings of the polymer chain. This decreases the degree of conjugation of the $\pi$-electron system and results in a hypsochromic shift of the absorption maxima in the electronic spectrum in comparison with unsubstituted PANI. ${ }^{94}$

\subsection{Thermal properties}

Numerous studies performed in recent years have shown that PANI is not only stable in aggressive chemical environments but also has high thermal stability, ${ }^{127-129}$ especially in the form of the emeraldine base, but it is less stable in doped state.

Four main stages of mass loss were identified for all the polymers. The first thermal transition corresponds to moisture evaporation. The second one is related to the removal of dopant impurity molecules. The third thermal transition corresponds to the loss of low molecular mass oligomers or side products (hydroquinone or quinone) or a substituent from the polymer chain, ${ }^{24}$ while the last one is due to the degradation of the main polymer chain. Literature sources report that PANI in the form of the emeraldine base is most stable even than all its substituted analogues. ${ }^{106}$

Comparative analysis of PANI derivatives in ref. 106 revealed that incorporation of substituents to the PANI aromatic ring leads to a decrease in thermal stability due to a decrease in the polymer molecular mass and the presence of a substituent (Fig. 17). PANI derivatives behave identically in doped state, too: they have lower heat resistance than their undoped forms. ${ }^{24,98,106,116}$

Thermogravimetric analysis of PANI derivatives showed that the presence of a halogen substituent at the aromatic ring reduces the thermal stability to $200^{\circ} \mathrm{C}$ (Fig. 18), whereas PANI is stable up to $300{ }^{\circ} \mathrm{C}$ (ref. 24) and in some cases, up to $500{ }^{\circ} \mathrm{C} .{ }^{106}$ PANI fluoro derivatives have the greatest stability in the series of halogenated PANI derivatives because fluorine has the smallest atomic radius among halogens, which results in smaller twisting of the macromolecular chain and a less noticeable decrease in the degree of conjugation..$^{24,98,116}$

The thermogravimetric curves obtained for the PANI bromo derivative show its lower thermal stability in comparison with PANI. Due to the large atomic radius of bromine, which increases the twisting and decreases the conjugation in the macromolecular chain in the series of PANI halogen derivatives, the heat resistance of poly-ortho-bromaniline is the smallest. ${ }^{27,137}$ It was found that PANI halogen derivatives have lower stability than alkylated derivatives, for example, poly-orthotoluidine. ${ }^{123}$

As shown by thermogravimetric analysis, incorporation of a hydrophilic group in the macromolecular chain decreases the thermal stability of functionalized PANI in comparison with the unsubstituted polymer. ${ }^{38,84} \mathrm{~A}$ loss of $\mathrm{HCl}$ occurs in the range of $60-100{ }^{\circ} \mathrm{C}$, the breakdown of the side bond occurs at $180-$ $280^{\circ} \mathrm{C}$, and the next stage at $320-400{ }^{\circ} \mathrm{C}$ involves the polymer destruction. ${ }^{82}$

The mass loss in the thermogravimetric analysis of polyortho-phenylenediamine and poly-meta-aminophenol occurred similarly to PANI. The degradation temperature was found to be $280{ }^{\circ} \mathrm{C}$ for the former derivative and $230{ }^{\circ} \mathrm{C}$ for the latter one. These temperatures are considerably lower than that of PANI.

In the testing of ferrocene-containing PANI, the thermal stability of the sample decreases in comparison with the initial one due to the catalytic effect of iron that favors the degradation of the polymer skeleton upon heat treatment. ${ }^{102}$

Data of thermogravimetric analysis of polyanthranilic acid show a gradual decomposition of the polymer synthesized by the classical method, which starts at $180{ }^{\circ} \mathrm{C}$ (Fig. 19).

In the case of a polyanthranilic acid sample obtained by interface polymerization, a sharp change in the "mass loss" parameter occurs at $240{ }^{\circ} \mathrm{C}$. A significant difference in the mass loss behavior of the last sample is apparently due to the appearance of a more regular chain length and the crystalline nature of the polymer synthesized under conditions of interface conversion of the low molecular compound to the high molecular one..$^{75,124-126}$

Thus, an increase in the degree of crystallinity of functionalized PANI samples positively affects the thermal stability of the polymer, shifting the decomposition start temperature to higher values.

\subsection{Morphological properties}

The oxidative polymerization of aniline and its derivatives is accompanied by the formation of an almost unlimited number of micro- and nanostructures with various sizes and shapes, including nanofibers, nanowires, nanotubes, hollow spheres, spirals, flowers and many others. ${ }^{130-133}$

Varying the synthesis conditions such as the concentration of reagents, $\mathrm{pH}$, homogeneous or heterogeneous 


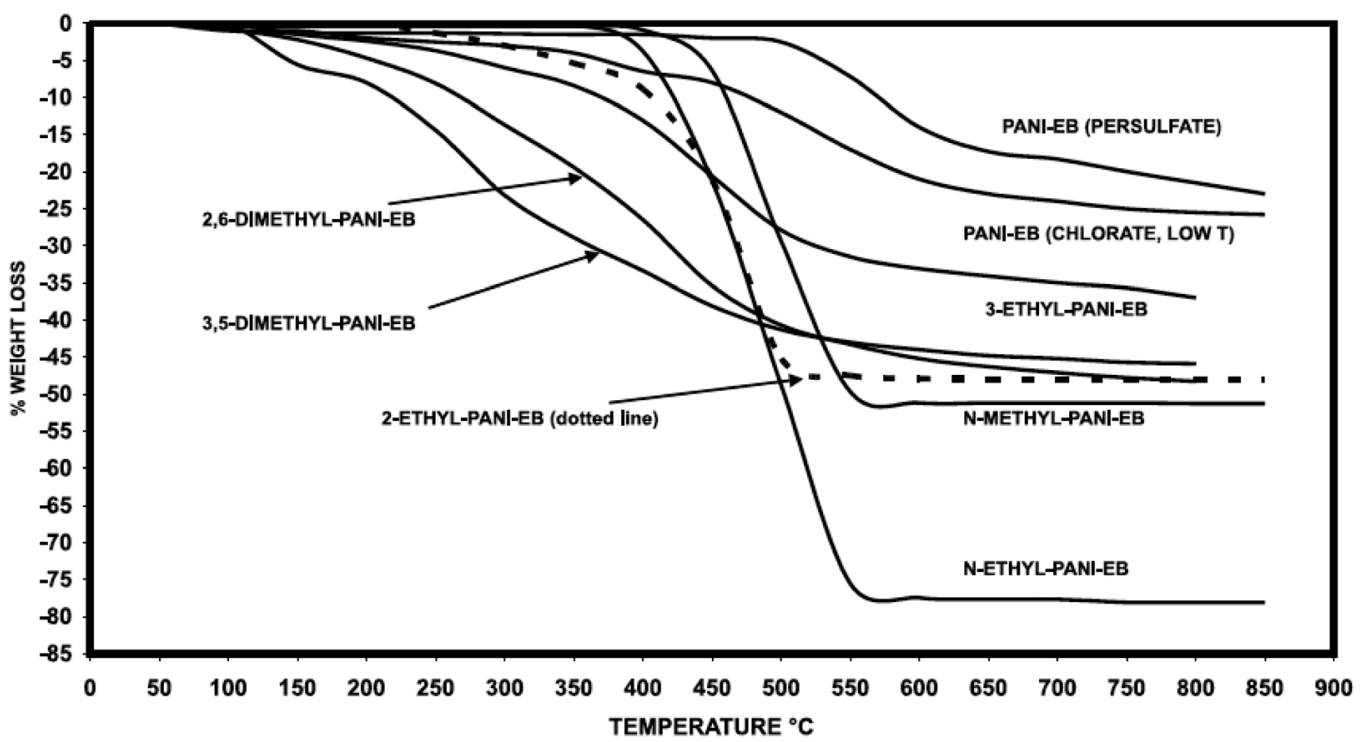

Fig. 17 Thermal stability of substituted PANI. Reproduced with permission from ref. 106.

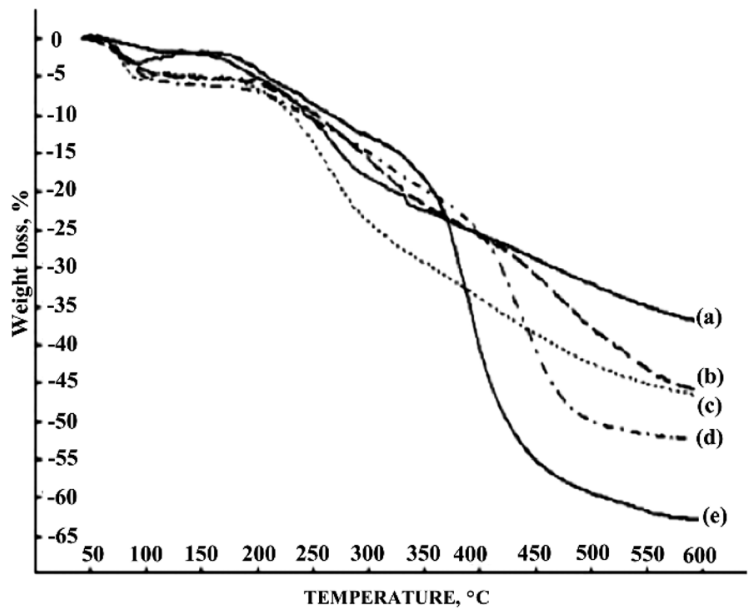

Fig. 18 Thermogravimetric curves of PANI (a), poly-2-fluoroaniline (b), poly-2-chloroaniline (c), poly-2-methylaniline (d) and poly- $N$ methylaniline (e). Reproduced with permission from ref. 98.

polymerization, rate of reagent addition, polymerization time, nature, amount and position of substituents in a wide range can decisively affect the nanoscale morphology of the resulting polymer. For this reason, both PANI itself and its derivatives have a potential for a significant contribution to the field of nano/macroscience, since there are almost no materials possessing such a morphological flexibility. All the facts described above allow one to study the structure-properties relationship for these nanoscale materials and develop potential applications that are adapted for various types of morphologies, depending on the required characteristics.

The morphology of polymers is studied using scanning electron microscopy. The most common morphology for PANI derivatives is a globular structure with different sphere sizes. In some cases, hollow nanospheres are formed. ${ }^{39,71}$ The hollow nanosphere morphology seems to be a potentially useful structure for various applications, for example, drug delivery and encapsulation, protection of sensitive chemical or biological species, ${ }^{132}$ and sensory devices. ${ }^{39,71}$

Functional groups in PANI structure allow various supramolecular structures to be obtained. ${ }^{39,45,71}$ For example, incorporation of methoxy and methyl groups to the ortho and meta positions of the PANI aromatic ring leads to the formation of hollow globules. ${ }^{39,71}$ This morphology is determined by the selfassembly method. ${ }^{135}$ The mechanism includes the initial formation of self-organized monomer micelles present at the initial reaction stage; they act as patterns in the formation of hollow nanospheres. Polymerization occurs at the micelle/water interface in the presence of hydrophilic APS oxidizer, then aggregation and fusion into larger spheres occurs, i.e., the nanospheres merge together. As polymerization continues, the monomers contained in the inner space of micelles diffuse to the surface, leading to the formation of hollow nanospheres. The diffusion of water and water-soluble components into the depth of the growing nanospheres probably favors the formation of holes on the surfaces that are visible on many hollow spheres. Hollow polymeric nanospheres can be obtained for poly-ortho-anisidine, poly-ortho-toluidine and poly-meta-toluidine. The type and position of the substituent at the aromatic ring affect the diameter of the hollow spheres (Fig. 20).

Under identical experimental conditions, the hollow spheres obtained from poly-toluidines were larger than those obtained from poly-ortho-anisidines. Apparently, this is due to the difference in the characteristics of $-\mathrm{OCH}_{3}$ and $-\mathrm{CH}_{3}$ groups, and the conversion of ortho-anisidine into the polymer occurs faster than that of toluidine. ${ }^{136}$ In turn, this means that smaller hollow nanospheres of poly-ortho-anisidine are formed more quickly than larger hollow nanospheres of polytoluidine. On the other hand, larger spheres were obtained from two ortho- and paratoluidines than from meta-toluidine. Probably, the steric effect 


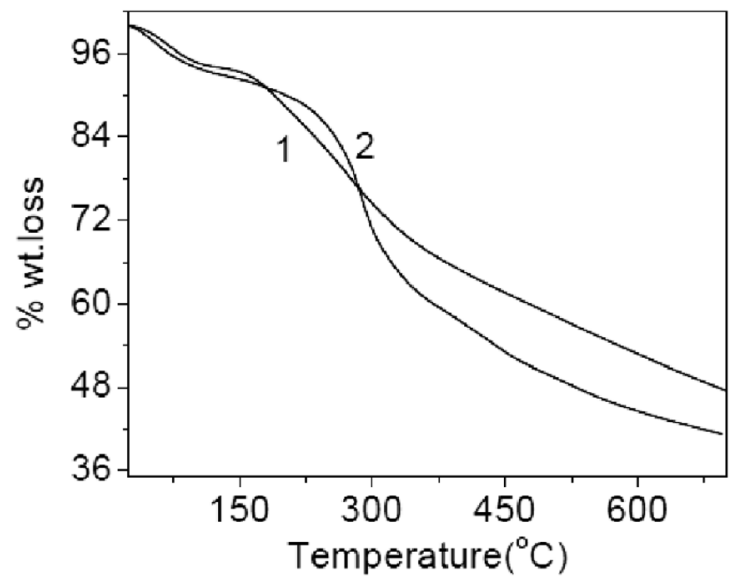

Fig. 19 Thermogravimetric curves of polyanthranilic acid obtained by: 1 - the classical method and 2 - interface polymerization. Reproduced with permission from ref. 80 .

of the methyl group that hinders polymerization "works" here, and its rate decreases. ${ }^{136}$ As a result, larger hollow nanospheres are formed due to the long formation time. ${ }^{39,71}$ The presence of hydroxy and carbonyl groups at the PANI aromatic ring also favors the formation of hollow nanospheres (Fig. 21). ${ }^{80,108}$ The polymerization conditions of anthranilic acid, ${ }^{80,124-126}$ orthohydroxyaniline and dihydroxyaniline ${ }^{\mathbf{1 0 7}}$ are similar to those used in the preparation of PANI with fibrillar morphology. The authors assume that the identified differences in the observed structures are directly due to the polymerization mechanism. ${ }^{108}$

A monomer that incorporates a hydrophilic hydroxy group and a hydrophobic aromatic ring behaves as an amphiphilic substrate. In water, hydrophilic substituents emerge to the outside and surround the aromatic ring to form micelles. Aggregation of such small monomeric micelles gives submicrometric groups that serve as patterns for polymer nanospheres. Subsequent oxidation of aggregated monomers produces nanospheres of a PANI hydroxy derivative. ${ }^{108}$

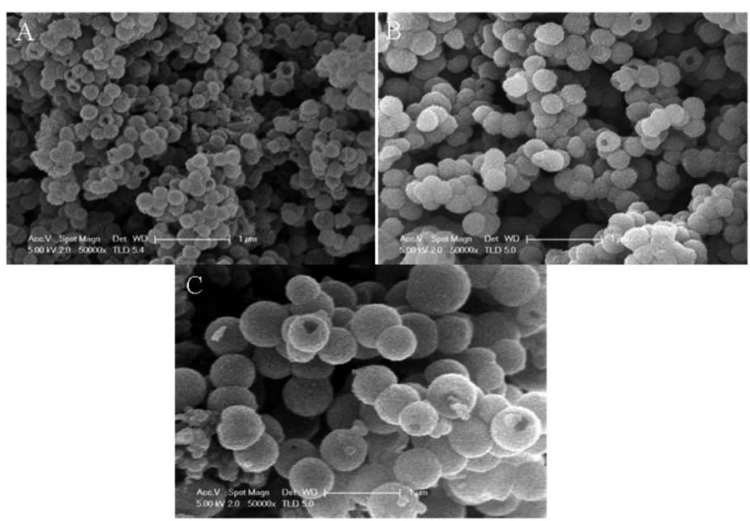

Fig. 20 SEM images of hollow nanospheres of substituted PANI synthesized in the presence of PMVEA. (A) Poly-ortho-anisidine, (B) poly-ortho-toluidine, (C) poly-meta-toluidine. Reproduced with permission from ref. 39 .
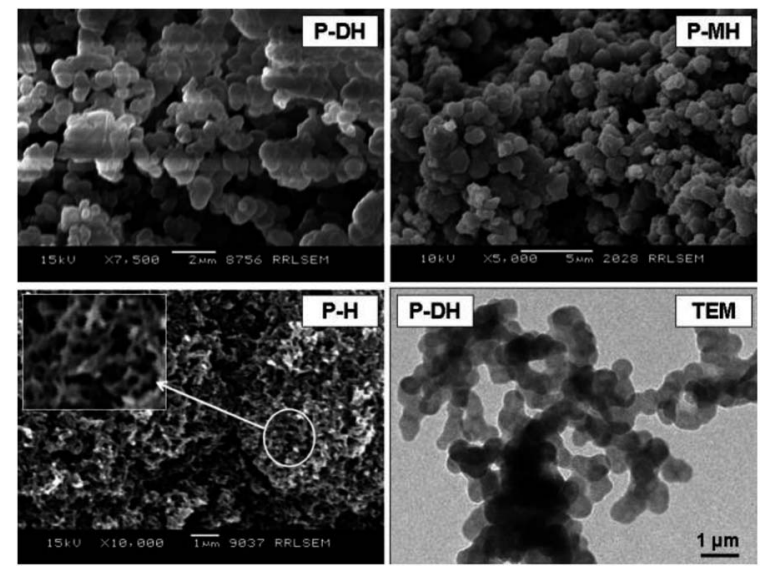

Fig. 21 SEM images of poly[2-(2,3-dihydroxypropoxy)aniline] (P-DH), poly[2-(2-hydroxyethoxy)aniline] $(\mathrm{P}-\mathrm{MH})$ and PANI $(\mathrm{P}-\mathrm{H})$. Reproduced with permission from ref. 108.

The supramolecular structures of PANI derivatives with various heteroatomic substituents, such as halogens, ferrocene and amino group, differ greatly.

In the series PANI $\rightarrow$ poly-ortho-fluoroaniline $\rightarrow$ poly-orthochloroaniline $\rightarrow$ poly-ortho-methylaniline, the morphology of polymers acquires increasingly well-defined forms of agglomerated spheres (Fig. 22). At the same time, PANI itself has the morphology of a network assembled from nanoparticles with 100-200 nm diameter and with irregular shapes, sizes and high surface area. ${ }^{24,98}$ It is interesting that the morphology of poly-3fluoroaniline established in ref. 24 had the form of nanoflakes (Fig. 23).

If the bulky heteroatomic ferrocene substituent is present in PANI, it significantly affects its morphology. ${ }^{102}$ A polymer with this substituent can form agglomerated particles well separated from each other, and its structure is more hollow and loose (Fig. 24). Such a porous structure favorably affects the contact of the electrode-active material with the electrolyte, providing sufficient ion channels for redox reactions during the charge/
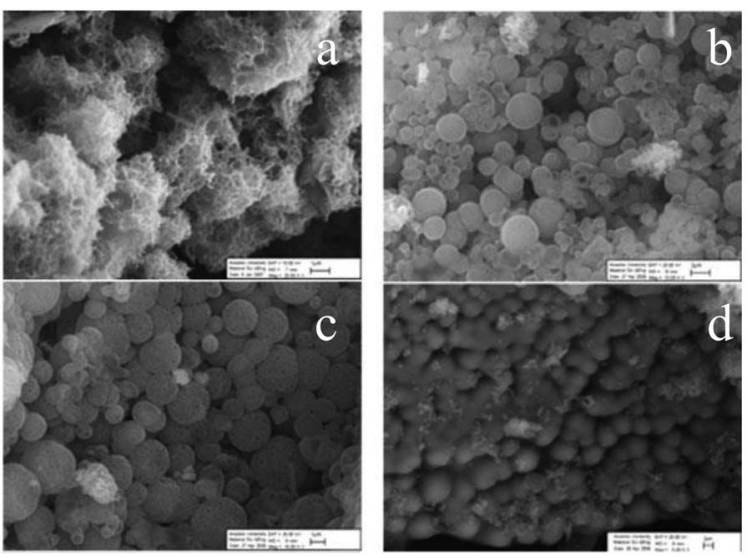

Fig. 22 SEM images of (a) PANI, (b) poly-2-fluoroaniline, (c) poly-2chloroaniline, and (d) poly-2-methylaniline. Reproduced with permission from ref. 98. 
discharge process. Note that this is very important for the preparation of a high-quality cathode material for lithium-ion cells. The specific surface area of the polymer increases significantly upon incorporation of such a substituent.

In 2011, a group of scientists ${ }^{\mathbf{1 3 0 - 1 3 2 , 1 3 4}}$ used nanostructures obtained with participation of an aniline tetramer to study the dependence of physical properties on intermolecular interactions. It was assumed that the morphology of PANI might depend on the type of nucleation: homogeneous nucleation of PANI produces nanofibers, whereas heterogeneous nucleation results in granular samples. ${ }^{\mathbf{8 4 , 1 3 8}}$ A study of PANI revealed that a polymer with fibrillar morphology had a higher electrical conductivity than those with other forms of supramolecular organization. ${ }^{\mathbf{1 3 1}}$ However, PANI derivatives with fibrillar structure are observed rather rarely. Substituted anilines undergo polymerization under conditions where PANI nanofibers are usually produced (rapid mixing, ${ }^{139}$ interfacial polymerization, ${ }^{\mathbf{1 4 0}}$ or polymerization in dilute solutions), and only irregularly shaped agglomerates are formed.

It was shown that homogeneous nucleation conditions should be created in the manufacture of PANI nanofibers in order to obtain a fibrillar structure. ${ }^{\mathbf{1 3 2 , 1 4 1}}$ This is primarily achieved by increasing the polymerization rate (increasing the reaction temperature, addition of an initiator). Intensifying the polymerization process increases the probability of the development of polymer nuclei to create homogeneous nucleation centers since diffusion to heterogeneous nucleation sites becomes limited. Initiator molecules whose redox potential is lower than that of the monomer can serve as nucleation centers for the growing macromolecular chains. ${ }^{65}$ This limits the diffusion of polymer nuclei to the heterogeneous nucleation centers. The low polymerization rate allows polymer nuclei to diffuse to heterogeneous nucleation sites, for example, to the side walls of a container, which leads to an agglomerated morphology.

Aniline polymerization on surfaces occurs faster than in the bulk, especially for substituted anilines. ${ }^{\mathbf{1 4 0}}$ Indeed, large amounts of the polymer is deposited on container side walls in ordinary reactions for producing substituted PANI. The films deposited on the side walls usually have a granular morphology. If a small amount of an additive, for example, para-phenylenediamine, was added to the system, the morphology of the

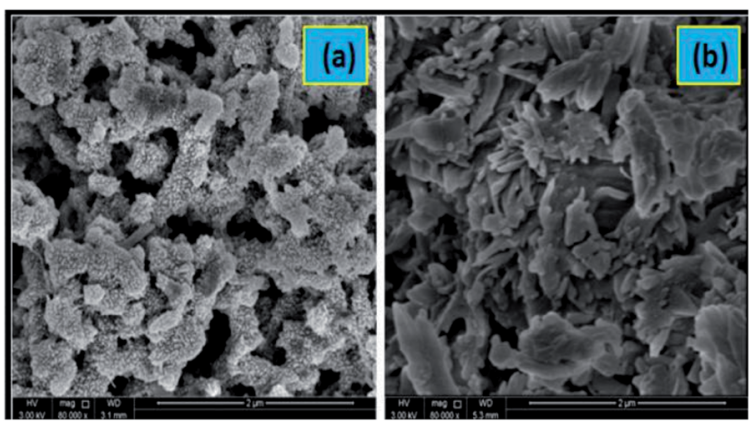

Fig. 23 SEM images of $\mathrm{HCl}$-doped forms of (a) PANI, (b) poly-3-fluoroaniline. Reproduced with permission from ref. 24.

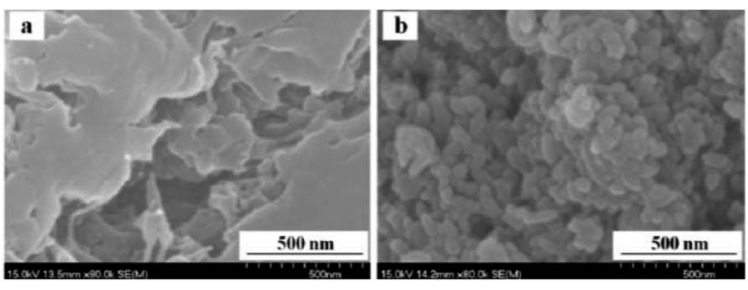

Fig. 24 SEM images of (a) PANI, (b) poly-6-(2-aminophenol-9H-yl)hexyl-ferrocene carboxylate. Reproduced with permission from ref. 102 .

resulting polymer changed from agglomerates to nanofibres and its formation occurred exclusively in the solution bulk..$^{\mathbf{1 3 2 , 1 3 4}}$ In the case of a PANI with a bulky hydrophobic substituent at the aromatic ring, i.e., poly[( \pm )-2-(cis-butyl)aniline], the presence of an additive results in uniform and less agglomerated spheres, which positively affects the electrical conductivity (Fig. 25). ${ }^{47,48}$

Changes in the conditions used for synthesizing PANI derivatives can dramatically change the morphology of polymers and hence their physicochemical properties. ${ }^{26}$ The size of high molecular particles usually decreases upon increasing the polymerization temperature, since the initiator decomposes faster under these conditions. An increase in the initiator decomposition rate results in a higher nucleation rate. ${ }^{\mathbf{1 4 2 - 1 4 4}}$

The use of ultrasonic or microwave radiation in the oxidative polymerization of aniline and its derivatives is an important way for achieving a nanoscale supramolecular structure in PANI and its derivatives. By changing the irradiation power and the reaction temperature, it is possible to control the size of the resulting particles, which is very important for the practical use of materials. ${ }^{49-61}$ The use of mechanical stirring during longlasting oxidative polymerization of aniline derivatives results in the agglomeration of particles and an increase in their average size. ${ }^{55}$ In contrast, ultrasonic or microwave irradiation efficiently prevents the growth and agglomeration of particles, thus preserving the PANI nanofibres in the final product. ${ }^{55}$ In view of this, the method for synthesizing PANI derivatives accompanied by irradiation appears convenient for large-scale production of polymers. ${ }^{60}$

The "calling card" of PANI is its high electrical conductivity, which depends on the amount and nature of the doping agent.
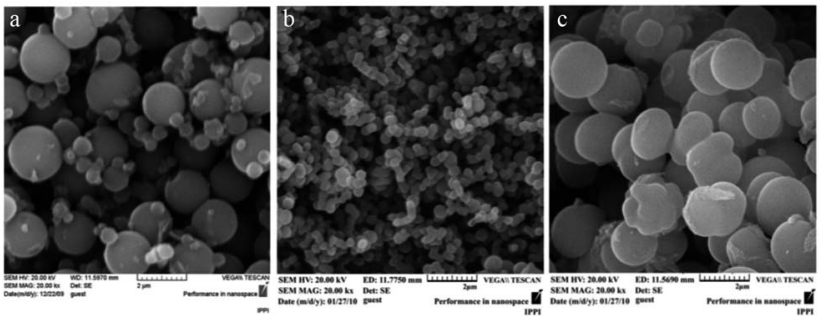

Fig. 25 SEM images of samples with $[( \pm)-2$-(cis-butyl)aniline $]=0.5 \mathrm{M}$; (a) without an initiator, (b) with phenylenediamine, and (c) with aniline dimer. Reproduced with permission from ref. 47. 
For example, the maximum electrical conductivity of poly-orthoanisidine is $169 \mathrm{~S} \mathrm{~cm}^{-1}$ at a doping agent/ortho-anisidine molar ratio of 8.00. This ratio ensures a totally fibrous morphology (diameter $65 \pm 8.6 \mathrm{~nm}$ ) (Fig. 26). ${ }^{145}$

One of the mechanisms of electrical conductivity, which is based on the effects of particle size and shape, involves the conductivity between particles due to with direct (ohmic) contact between them. A smaller particle size provides a more efficient conductive network due to a more developed surface, which increases charge transfer and hence electrical conductivity. Moreover, the particle shape also affects electrical conductivity. If the particle shape is characterized by a large area of conductive contacts with adjacent particles, it provides the maximum charge transfer and favors high electrical conductivity. Thus, the fibrillar morphology provides the best binding between the neighboring particles and the highest electrical conductivity of polymer samples. ${ }^{\mathbf{1 4 4 - 1 4 7}}$

\section{Quantum-chemical study of the structure and properties of PANI derivatives}

The physicochemical properties of high molecular electrically conductive materials can be improved by modifying the main chain. Theoretical calculations allow one to develop new, more perfect organic systems with optimum parameters.

The key property of PANI is that it has controlled electronic conductivity. In order to ensure this quality, the polymer requires a set of characteristics. The characteristics desirable for an conductive organic material include: (1) low energy value of the first optical transition (HOMO-LUMO); (2) high stability; (3) good machinability; (4) large nonlinear optical response. The physical and chemical parameters are improved primarily by side groups of the macromolecular chain. For example, electron-withdrawing substituents affect the LUMO orbital; therefore, they change the energy of the HOMO-LUMO

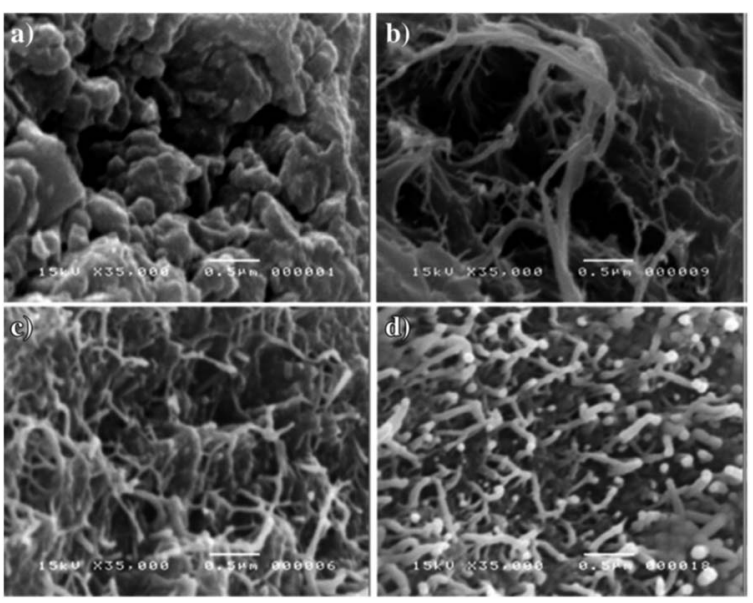

Fig. 26 Morphology of poly-ortho-anisidine obtained with SDS with various molar ratios: (a) 0.008 , (b) 4.00 , (c) 8.00 and (d) 10.00 . Reproduced with permission from ref. 26. transition. In addition, type II orientants increase the ionization potential and, in principle, increase the system stability to oxidation reactions.

Using theoretical calculations, it was shown that incorporation of electron-withdrawing groups to the PANI's aromatic core decreases the band gap and the energy of the first optical transition, presumably due to steric and electronic effects of substituents. ${ }^{\mathbf{1 4 8 - 1 5 0}}$

It the first theoretical study on the effect of substituents on the properties of $\mathrm{PANI},{ }^{\mathbf{1 4 8 , 1 4 9}}$ the results of the presence of functional groups $\left(-\mathrm{NH}_{2},-\mathrm{OH},-\mathrm{CO}_{2} \mathrm{H},-\mathrm{Cl},-\mathrm{CF}_{3},-\mathrm{CH}_{3},-\mathrm{OCH}_{3}\right.$, $-\mathrm{CN},-\mathrm{NO}_{2}$ ) at benzene ring positions 2 or 3 were analyzed in order to determine whether it is possible to obtain a molecule with a low band gap even in reduced state. It was shown ${ }^{\mathbf{1 4 9}}$ that the electron distribution and polymer geometry substantially depend on the substituent attached to the macromolecule, and the last three substituents, i.e., $-\mathrm{OCH}_{3},-\mathrm{CN},-\mathrm{NO}_{2}-$ show a noticeable response. The nitro group has the maximum effect on PANI: hydrogen bonds are formed between the hydrogen at the nitrogen atom of the terminal amino group and the oxygen atom of the nitro group and a strong perturbation of the difference LUMO (nitro group) - LUMO (rings). As a result, PANI samples containing the $\mathrm{NO}_{2}$ group have excellent electronic properties. The calculated ultraviolet radiation spectrum of this product shows the first optical transition at $380 \mathrm{~nm}$; it will have semiconductor properties, even in reduced state. ${ }^{\mathbf{1 4 8}}$

The method of controlling the chemical and electronic properties of PANI by introducing suitable functional groups to the aromatic ring of the polymer presented in ref. 151 is of noticeable interest. Using the density functional theory method, it was demonstrated that the presence of $-\mathrm{OH}$ and $-\mathrm{SO}_{3} \mathrm{Na}$ groups significantly increased the chemical activity in the PANI protonation reaction. Carbonic acid acted as a doping agent in this case. An important conclusion made in this study is that the HOMO and LUMO distributions in non-protonated PANI are almost insensitive to the functional group. At the same time, the LUMO distribution in PANI doped with carbonic acid obviously changes depending on the substituent nature. It is believed that differences in LUMO distribution change the band gap in protonated states. Moreover, comparative analysis of the effect of $-\mathrm{OH}$ and $-\mathrm{SO}_{3} \mathrm{Na}$ on the properties shows that both chemical and electronic properties are highly sensitive to the polarity and size of functional groups. ${ }^{151}$

In a theoretical study of the effect of substituents on PANI properties, Zhang $\mathrm{Y}^{.152}$ examined the nature of the charge transfer mobility of aniline tetramer and its ortho-chloro derivative. It was found that the electron mobility in an aniline tetramer crystal is much higher than that in a 2-chloroaniline tetramer crystal. Therefore, the use of aniline tetramer as an ntype organic semiconductor is preferable. A similar conclusion can be reached on the basis of density of states: an aniline tetramer crystal showing a higher electron density should have a higher conductivity that is proportional to the charge transfer mobility. ${ }^{152}$

A theoretical study of the effect of various substituents on the electronic and structural characteristics of PANI confirms that the presence of substituents in the PANI macromolecular chain 
results in a decrease in electron mobility and hence a decrease in conductivity.

\section{Applications}

PANI derivatives occupy a central position among conductive macromolecular compounds developed for various applications. ${ }^{153,154}$ The processing properties of PANI vary widely upon incorporation of functional groups, which results in an even greater expansion of the application range of these polymers.

\subsection{Sensors}

Electrically conductive PANI derivatives became popular as competent measuring materials for a variety of organic vapors, ${ }^{155}$ hazardous gases, ${ }^{156}$ and humidity. ${ }^{157}$

The development of a new generation of sensor devices is mainly associated with two electrically conductive polymers, namely, PANI and polypyrrole. Polymers serve as the detecting component in sensors since they are sensitive to chemical reagents and give a consistent response to them. The sensors are intended for determination of the concentrations of toxic and explosive gases, organic solvents and acids, narcotic compounds, amino acids, etc. Highly selective devices for the diagnostics of gas and liquid mixtures under the names "electronic nose" and "electronic tongue" are being developed.

Each of the existing PANI forms, i.e., leucoemeraldine, emeraldine, and pernigraniline, demonstrates a variety of colors, conductivity and stability. Sensors are manufactured taking into account the changes in the properties of the three PANI forms upon interaction with an analyte. The experimental characteristics of PANI-based devices can be improved by incorporating functional groups at the PANI's aromatic ring. ${ }^{157}$

Optical sensors for $\mathrm{pH}$ determination based on the following derivatives have been created and are operative: poly-2chloroaniline, poly-2-bromoaniline, poly-3-chloroaniline, polyortho-toluidine, poly-diphenylamine. ${ }^{42-44,81,159} \mathrm{pH}$ measurements are based on recording the changes in the optical properties of the corresponding material caused by $\mathrm{pH}$ variation. ${ }^{81,158}$

Of the self-doped PANI family, PANI substituted with boric acid is the most interesting option because of its adjustable electronic and optical properties related to the acid group in the substituent. It is used in sensors for the detection of biologically important molecules such as saccharides, ${ }^{160-163}$ nucleotides ${ }^{164}$ and dopamine. ${ }^{165,166}$

Nanofibers of polyanilineboric acid demonstrate highly sensitive detection of $\mathrm{D}$-glucose in phosphate-buffered solution $(\mathrm{pH}=7.4)$. The fibrillar morphology of the polymer exhibits better electrochemical redox activity than agglomerates. ${ }^{166-169}$

It is known that a problem of dopamine detection in the presence of ascorbic acid exists. ${ }^{45}$ Poly-2-amino-4hydroxybenzenesulfonic acid obtained by $\mathrm{S}$. $\mathrm{Mu}^{45}$ and used as a material for determining dopamine in the presence of ascorbic acid showed high selectivity to the analyte. The results are explained by the synergistic effect of the $-\mathrm{SO}_{3}$ and $-\mathrm{OH}$ groups present in the poly-2-amino-4-hydroxybenzenesulfonic acid chain. The activity of the polymer toward dopamine can be due to the high redox activity of poly-2-amino-4hydroxybenzenesulfonic acid and the $\mathrm{SO}_{3}$ group in its chain. ${ }^{45}$

Poly-ortho-methoxyaniline was used in gas sensors. ${ }^{170}$ Their response to an environmentally important gas, sulfur dioxide that belongs to the "acid gases" category, was studied in real time. Since PANI has pronounced acid-base properties, it provides the best molecular and/or physical interaction between the target gas and the sensitive material, which is a prerequisite for selective gas adsorption in a sensor. The recommendation was given that at low sulfur dioxide concentrations (below the threshold of $250 \mu \mathrm{g} \mathrm{kg}^{-1}$ ), a gas sensor based on poly-2-methoxyaniline can be used to determine its content, and when the amount of $\mathrm{SO}_{2}$ increases, it can serve as an adsorbent material to remove the toxic gas from the atmosphere. This allows one to create a new unique gas filter and/or reservoir for contaminant storage. ${ }^{170,171}$

Based on a water-soluble electrically conductive polydiphenylamine sulfonic acid, a humidity sensor was created with high stability, fast response and recovery, and low hysteresis in almost the entire humidity range. ${ }^{172}$

Using functionalized PANI (poly-ortho-anisidine, poly-orthochloroaniline, poly-ortho-ethoxyaniline), devices for nitrate removal were created. ${ }^{173} \mathrm{~A}$ study on the efficiency of these samples in a real environment showed that $40 \%$ of nitrate ions were adsorbed on conductive polymers within 30 minutes, despite the presence of a considerable amount of anions and cations that prevent the removal of nitrates. ${ }^{173}$

\subsection{Anti-corrosion coatings}

Bearing in mind that $10-15 \%$ of the metal produced annually is degraded due to corrosion, the intensification of the efforts for its prevention undertaken by scientists is quite understandable. For example, DuPont and Zipperling Kessler manufacture anticorrosive paint coatings for the protection of ferrous and non-ferrous metals in which PANI is used as a non-toxic corrosion inhibitor. Its advantage lies in the ability to provide anodic passivation of the metal and inhibit corrosion processes not only under the film coating but also in the vicinity of its defects.

In 2007, Ahmad et al. ${ }^{174,175,180}$ developed an anticorrosion protection method based on polynaphthylamine. The conclusions on the corrosion resistance of mild steel in acidic, basic and salt media in the presence of polynaphthylamine were based on open circuit potential measurements. The high corrosion protection indicators observed in this case (in comparison with traditional coatings) are attributed to the ability of polynaphthylamine to pass to an oxidized state that passivates the metal for a long period of time.

The results on the corrosion protection by substituted anilines, ortho-, meta-toluidines, ortho-anisidine and orthochloroaniline electrochemically polymerized on iron surface showed that the latter monomer formed a non-conductive film with weak anticorrosion properties in acid media. ${ }^{176-179}$ Relatively strong adhesive polymeric films formed from the remaining three substituted anilines. These films demonstrated protective properties in sulfuric acid solutions by stabilizing the 
passive state of iron. Nevertheless, comparison of the anticorrosive behavior of the films formed from PANI and its functionalized derivative studied by Barker et al. ${ }^{157}$ allows us to conclude that the former has superior properties. It is worthy of note here that the corrosion protection of iron in acid solutions increases due to improvement of the adhesive properties of the polymer which, in turn, like solubility, are improved upon transition from PANI to substituted PANI derivatives.

\subsection{Energy carriers}

In comparison with high-molecular conductive compounds such as polypyrrole and polythiophene, PANI is believed to be a more attractive material for electrodes in supercapacitors due to its high capacitance and excellent electrical conductivity. PANI has a set of properties necessary for a material for supercapacitors or battery electrodes, namely, high electroactivity and sufficient doping level, stability in acid environments, and high specific capacitance $\left(400-500 \mathrm{~F} \mathrm{~g}^{-1}\right){ }^{181-191}$

Despite the fact that the service life of a positive electrode based on Li-doped PANI is more than 5000 cycles, ${ }^{185}$ studies aimed at improving this parameter are continuing, and PANI derivatives have been suggested as electrode materials. ${ }^{26}$ For example, polyanisidine films have high specific capacity and good electrochemical stability for 3000 cycles, while the specific power remains unchanged. The use of conductive macromolecular compounds in ionic liquids demonstrates the stability of samples intended for use in supercapacitors. ${ }^{26}$ In particular, fairly good supercapacitor characteristics comparable with those of PANI-based samples, such as charge/discharge ability and electrochemical impedance, were obtained for samples of poly-ortho-anisidine and poly-ortho-toluidine in $2 \mathrm{M} \mathrm{H}_{2} \mathrm{SO}_{4}$ medium. ${ }^{181,192}$

The performance and stability of an electrochemical capacitor based on doped PANI derivatives obtained by deposition on a stainless steel electrode were studied in direct current mode and showed specific capacitances from 110 to $177 \mathrm{~F} \mathrm{~g}^{-\mathbf{1}} .^{193}$

Materials based on PANI containing a disulfide bridge in the side chain, poly[bis(2-aminophenyloxy)disulfide], were found to be of interest for energy carriers. ${ }^{\mathbf{1 0 0}}$ Based on the cyclic voltammograms of this compound, it can be stated that intramolecular self-catalysis occurs in the main chain of the conducting PANI (doping/dedoping processes in the $\mathrm{p}$ conjugated system) and in the disulfide bond of the macromolecule's framing (breakdown/formation of S-S bonds) of poly [bis(2-aminophenyloxy)disulfide]. Since the oxidation-reduction processes in the main chain of the conducting PANI occur in the same potential range as in the side disulfide bonds, the $\mathrm{Li} /$ poly[bis(2-aminophenyloxy)disulfide] test cell shows a charge capacity of $230 \mathrm{~mA} \mathrm{~h}^{-1} \mathrm{~g}^{-1}$ and an energy density of $460 \mathrm{~mW}$ $\mathrm{h}^{-1}$ for the cathode, which are $c a .2$ times higher than similar parameters for inorganic compounds. ${ }^{101}$

Ferrocene-containing polymers are quite promising as materials for organic cathodes in lithium-ion cells. ${ }^{\mathbf{1 0 2}}$ They are capable of accelerated charge/discharge and have flat and stable floating voltages. Though the internal conductivity of ferrocenecontaining polymers is rather low, combinations of electroactive ferrocene with a conductive high molecular compound are considered to be an efficient method for obtaining a new polymer with improved electrical conductivity. In particular, charge/discharge tests with a ferrocenecontaining polymer as a cathode material in lithium-ion cells showed an improvement in the discharge plateau, along with an acceptable initial discharge specific capacity of $104.9 \mathrm{~mA} \mathrm{~h}^{-1}$ (108 $\mathrm{mA} \mathrm{h}^{-1}$ for PANI). However, the ferrocene-containing PANI derivative exhibits improved cycling stability in comparison with PANI. ${ }^{102}$

\subsection{Biological significance}

The studies of PANI in biomedical areas are extremely promising. The polymer is non-toxic and was recently shown to be biocompatibile. ${ }^{73}$ Enzymes, antibodies, and living cells bound to the polymer preserve their biological activity. Accelerated non-invasive growth of cells and neurites on a polymer carrier under the influence of electric field is observed. Data are available concerning the use of PANI as a temporary matrix for attaching cells to implants and as a biocompatible electrode: electrical signals applied to the polymer layer deposited in vivo favored the acceleration of tissue regeneration.

The keen interest in sulfonated PANI is due to the fact that the $-\mathrm{SO}_{3} \mathrm{H}$ group at the aromatic ring considerably improves the solubility and ecological stability of a compound without a noticeable decrease in electrical conductivity. ${ }^{72}$ At the same time, the conductivity of sulfonated PANI does not depend on external protonation in a wide $\mathrm{pH}$ range. What is more, this polymer has higher thermal stability than HCl-doped PANI.

Encouraging results were obtained ${ }^{72,73}$ in studies on the cytocompatibility of sulfonated PANI in in vitro cultures with cells of malignant human osteosarcoma that is the most difficult to cure. Microscopic observation showed no abnormal cell behavior upon direct contact of sulfonated PANI with osteosarcoma cells.

Quite a few reports on the antibacterial action of PANI and its derivatives are available in literature. The results presented in the publications indicate that undoped functionalized PANI samples (with $-\mathrm{OCH}_{3},-\mathrm{SO}_{3} \mathrm{H}$, and $-\mathrm{OH}$ groups) are efficient against various infections, whereas doped polymers are active only in media with $\mathrm{pH}>3$ due to instability of functional groups. Incorporation of such functional groups as $-\mathrm{SO}_{3} \mathrm{H}$ and $-\mathrm{COOH}$ in the PANI aromatic ring favors the inhibition of the growth of wild-type Gram-negative and Gram-positive bacteria and medically important antibiotic-resistant bacteria. ${ }^{194}$ The bactericidal activity of PANI derivatives is due to their ability to destroy cell wall membranes leading to cell death. ${ }^{195,196}$ An important advantage of polymeric bactericidal materials is that they are used at low concentrations, unlike some conventional antibiotics and natural bactericides. ${ }^{194,196-199}$ In addition, a PANI derivative with a carboxy group was studied as an antituberculous drug. ${ }^{200}$ It was found that the antimicrobial effect of the polymer studied was already achieved after 15 minutes of active exposure to its $2 \%$ solution. Alkyl-substituted PANI derivatives also exhibit antibacterial activity. ${ }^{201}$ In the series including 
PANI, poly-o-toluidine and poly-o-ethylaniline, the greatest inhibition of bacterial growth was provided by poly- $o$-toluidine.

Bromine, both in ionic state and in compounds with covalent bonds, is known to have pronounced bactericidal properties. $^{27,179}$ Therefore, its incorporation in the PANI macromolecular chain is promising in terms of producing a component for antimicrobial coatings. It is also important that, unlike conventional antibacterial agents, brominated PANI has both an anti-fouling property and an excellent anticorrosion effect. This polymer can be recommended as an additive to coatings, primarily for the protection of steel from electrochemical corrosion and biofouling.

It appears that the antioxidant properties of PANI derivatives is an important area in the studies of their properties. ${ }^{202-205}$ Conductive polymeric nanostructures with good biocompatibility combined with the antioxidant property to prevent hemolysis can lead to a tremendous progress in the fields of biomedicine and controlled drug release. The latter can be extremely useful in cancer treatment. ${ }^{204}$ According to literature data, PANI and its derivatives are good reducing agents and efficient free radical scavengers. ${ }^{\mathbf{2 0 4 , 2 0 5}}$ The antioxidant properties of PANI derivatives result from their redox ability. The absorption of radicals by a polymer occurs by conversion of - $\mathrm{NH}-$ and $-\mathrm{N}^{+}$- groups to completely oxidized $-\mathrm{N}=$ groups, as detected by IR spectroscopy and CV. ${ }^{206}$ The antioxidant ability of conductive polymers is important for their incorporation as biomaterials into biological media. ${ }^{205}$

Along with the properties mentioned above, polyaniline derivatives have good adsorption ability that was successfully applied in the field of water purification from various dyes. ${ }^{\mathbf{2 0 7 - 2 1 0}}$ The phenomenon of adsorption of a paint pigment on the polymer was explained by a change in the surface charge upon protonation of the amine group in PANI derivatives ${ }^{\mathbf{2 0 7}}$ which allows one to achieve a high degree of adsorption of both cationic and anionic dyes. The high adsorption efficiency is probably due to a higher porosity or a large number of active binding sites, which results in improved ion exchange properties and favors the absorption of a dye molecule..$^{\mathbf{2 0 8 - 2 1 0}}$

\section{Conclusions}

The information presented in the review allows us to state the following. Regardless of the method for producing modified PANI and the nature of incorporated functional groups, the electrical conductivity of materials decreases to a various extent in comparison with PANI: the decisive role in this effect is played by electronic and steric effects. Owing to fibrillar morphology, the best binding between adjacent particles is reached and high values of electrical conductivity of polymer samples are achieved. Interface polymerization, which ensures the highest degree of crystallinity of the target product and, accordingly, the best conductivity, appears to be the optimum way for the conversion low molecular mass substituted anilines into high molecular ones. However, the loss in electrical conductivity of functionalized PANI are compensated by a significant improvement in their operational characteristics, such as increased solubility, energy capacity, improved adhesion and the corresponding anticorrosive effect of coatings.

\section{Conflicts of interest}

There are no conflicts to declare.

\section{Acknowledgements}

This work was supported by the Ministry of Science and Higher Education of the Russian Federation as part of the state task no. AAAA-A19-119020890014-7.

\section{Notes and references}

1 M. Ghoswami, R. Ghosh, G. Chakraborty, K. Gupta and A. K. Meikap, Polym. Compos., 2011, 32, 2017.

2 G. Inzelt, in Conducting polymers: a new era in electrochemistry, Springer Science \& Business Media, 2012, p. 310 .

3 K. M. Molapo, P. M. Ndangili, R. F. Ajayi, G. Mbambisa, S. M. Mailu, N. Njomo and E. I. Iwuoha, Int. J. Electrochem. Sci., 2012, 7, 11859.

4 H. S. Abdulla and A. I. Abbo, Int. J. Electrochem. Sci., 2012, 7, 10666.

5 R. Gracia and D. Mecerreyes, Polym. Chem., 2013, 4, 2206.

6 Y. Wang and X. Jing, Polym. Adv. Technol., 2005, 16, 344.

7 S. Bhadra, N. K. Singha and D. Khastgir, Polym. Eng. Sci., 2008, 48, 995.

8 Y. Qiao, C. M. Li, S. J. Bao and Q. L. Bao, J. Power Sources, 2007, 170, 79.

9 J. Chen, B. Li, J. Zheng, J. Zhao, H. Jing and Z. Zhu, Electrochim. Acta, 2011, 56, 4624.

10 X. Wei, L. Jiao, J. Sun, S. Liu and H. Yuan, J. Solid State Electrochem., 2010, 14, 197.

11 P. Lin and F. Yan, Adv. Mater., 2012, 24, 34.

12 T. Ahuja, I. A. Mir, D. Kumar and A. Rajesh, Biomaterials, 2007, 28, 791.

13 M. Ates, J. Adhes. Sci. Technol., 2016, 30, 1510.

14 M. R. Choi, T. H. Han, K. G. Lim, S. H. Woo, D. H. Huh and T. W. Lee, Angew. Chem., Int. Ed., 2011, 50, 6274.

15 S. H. Hong, O. Kim, S. Choi and M. Ree, Appl. Phys. Lett., 2007, 91, 093517.

16 A. W. Marsman, C. M. Hart, G. H. Gelinck, T. C. T. Geuns and D. M. de Leeuw, J. Mater. Res., 2004, 19, 2057.

17 S. Lakard, J. Husson, S. Monney, C. C. Buron and B. Lakard, Prog. Org. Coat., 2016, 99, 429.

18 P. Wang, K. L. Tan, F. Zhang, E. T. Kang and K. G. Neoh, Chem. Mater., 2001, 13, 581.

19 A. Watanabe, K. Mori, A. Iwabuchi, Y. Iwasaki, Y. Nakamura and O. Ito, Macromolecules, 1989, 22, 3521.

20 K. Yamabe, K. Nakajima and H. Goto, J. Polym. Sci., Part A: Polym. Chem., 2018, 56, 805.

21 C. Barbero, H. J. Salavagione, D. F. Acevedo, D. E. Grumelli, F. Garay, G. A. Planes and M. C. Miras, Electrochim. Acta, 2004, 49, 3671.

22 M. Jaymand, Prog. Polym. Sci., 2013, 38, 1287. 
23 M. Heydari, P. Najafi Moghadam, A. R. Fareghi, M. Bahram and N. Movagharnezhad, Polym. Adv. Technol., 2015, 26, 250.

24 U. S. Waware, G. J. Summers, A. M. S. Hamouda and M. Rashid, Polym.-Plast. Technol. Eng., 2018, 57, 1015.

25 U. S. Waware, G. J. Summers, M. Rashid and A. M. S. Hamouda, Ionics, 2018, 24, 1701.

26 K. Khamngoen, N. Paradee and A. Sirivat, J. Polym. Res., 2016, 23, 172.

27 W. Cai, J. Wang, X. Quan and Z. Wang, J. Appl. Polym. Sci., 2018, 135, 45657.

$28 \mathrm{H}$. Higashimura and S. Kobayashi, in Encyclopedia of Polymer Science and Technology, John Wiley \& Sons, 2016, p. 37.

29 M. M. Gvozdenović, B. Jugović, J. S. Stevanović and B. Grgur, Chem. Ind., 2014, 68, 673.

30 P. K. Prabhakar, S. Raj, P. R. Anuradha, S. N. Sawant and M. Doble, Colloids Surf., B, 2011, 86, 146.

31 F. Zeng, Z. Qin, B. Liang, T. Li, N. Liu and M. Zhu, Prog. Nat. Sci.: Mater. Int., 2015, 25, 512.

32 J. Stejskal and M. Trchova, Polym. Int., 2012, 61, 240.

33 E. Ahlatcioğlu, B. F. Senkal, M. Okutan and Y. Gursel, Mater. Sci. Semicond. Process., 2014, 28, 103.

34 M. Bláha, M. Riesová, J. Zedník, A. Anžlovar, M. Žigon and J. Vohlídal, Synth. Met., 2011, 161, 1217.

35 H. J. Salavagione, J. Electroanal. Chem., 2016, 765, 118.

36 E. Ortega, F. Armijo, I. Jessop, M. A. Del Valle and F. R. Díaz, J. Chil. Chem. Soc., 2013, 58, 1959.

37 H. Goto and K. Akagi, Macromolecules, 2002, 35, 2545.

38 E. Ahlatcioğlu, B. F. Senkal, M. Okutan and Y. Gursel, Mater. Sci. Semicond. Process., 2014, 28, 103.

39 J. Sui, W. Li and Q. Pan, J. Macromol. Sci., Part B: Phys., 2017, 56, 623.

40 W. Shenglong, W. Fosong and G. Xiaohui, Synth. Met., 1986, 16, 99.

41 S. Cattarin, L. Doubova, G. Mengoli and G. Zotti, Electrochim. Acta, 1988, 33, 1077.

42 T. Amaya, Y. Abe, Y. Inada and T. Hirao, Tetrahedron Lett., 2014, 55, 3976.

43 T. Amaya, I. Kurata, Y. Inada, T. Hatai and T. Hirao, $R S C$ Adv., 2017, 7, 39306.

44 W. L. Hsu and P. C. Wang, in Next-Generation Electronics (ISNE), 2016 5th International Symposium on. IEEE, 2016, p. 1.

45 S. Mu, J. Phys. Chem. B, 2008, 112, 6344.

46 Y. Wei, G. W. Jang, C. C. Chan, K. F. Hsueh, R. Hariharan, S. A. Patel and C. K. Whitecar, J. Phys. Chem. A, 1990, 94, 7716.

47 F. Movahedifar and A. R. Modarresi-Alam, Polym. Adv. Technol., 2016, 27, 131.

48 A. R. Modarresi-Alam, H. A. Amirazizi, F. Movahedifar, A. Farrokhzadeh, G. R. Asli and H. Nahavandi, J. Mol. Struct., 2015, 1083, 17.

49 A. Abdelraheem, A. H. El-Shazly and M. F. El-Kady, Mater. Sci. Forum, 2016, 860, 12.

50 H. Ahmadizadegan and S. Esmaielzadeh, Solid State Sci., 2018, 85, 9.
51 S. Arulmani, J. J. Wu and S. Anandan, Ultrason. Sonochem., 2019, 51, 469-477.

52 J. Manuel, M. Kim, D. Fapyane, I. S. Chang, H. J. Ahn and J. H. Ahn, Mater. Res. Bull., 2014, 58, 213.

53 M. Atobe, A. N. Chowdhury, T. Fuchigami and T. Nonaka, Ultrason. Sonochem., 2003, 10, 77.

54 A. N. Chowdhury, M. Atobe and T. Nonaka, Ultrason. Sonochem., 2004, 11, 77.

55 X. Jing, Y. Wang, D. Wu and J. Qiang, Ultrason. Sonochem., 2007, 14, 75.

56 Y. Li, Y. Wang, D. Wu and X. Jing, J. Appl. Polym. Sci., 2009, 113, 868.

57 M. Jevremovic, Z. Zujovic, D. Stanisavljev, G. Bowmaker and M. Gizdavic-Nikolaidis, Curr. Appl. Phys., 2014, 14, 1201.

58 S. Pandey and J. Ramontja, Int. J. Biol. Macromol., 2016, 89, 89.

59 M. R. Gizdavic-Nikolaidis, D. R. Stanisavljev, A. J. Easteal and Z. D. Zujovic, Macromol. Rapid Commun., 2010, 31, 657.

60 M. R. Gizdavic-Nikolaidis, D. R. Stanisavljev, A. J. Easteal and Z. D. Zujovic, J. Phys. Chem. C, 2010, 114, 18790.

61 M. R. Gizdavic-Nikolaidis, M. Jevremovic, D. R. Stanisavljev and Z. D. Zujovic, J. Phys. Chem. C, 2012, 116, 3235.

62 E. Kim, N. Kang, J. J. Moon and M. Choi, Bull. Korean Chem. Soc., 2016, 37, 1445.

63 G. D'Aprano, M. Leclerc and G. Zotti, J. Electroanal. Chem., 1993, 351, 145.

64 C. H. Yang, J. Electroanal. Chem., 1998, 459, 71.

65 G. D'Aprano, M. Leclerc, G. Zotti and G. Schiavon, Chem. Mater., 1995, 7, 33.

66 M. R. Presa, D. Posadas and M. I. Florit, J. Electroanal. Chem., 2000, 482, 117.

67 T. Lindfors and A. Ivaska, J. Electroanal. Chem., 2002, 531, 43.

68 H. Jiang, Y. Geng, J. Li, X. Jing and F. Wang, Synth. Met., 1997, 84, 125.

69 S. I. C. de Torresi, A. N. Bassetto and B. C. Trasferetti, J. Solid State Electrochem., 1998, 2, 24.

70 Y. Wei, W. W. Focke, G. E. Wnek, A. Ray and A. G. MacDiarmid, J. Phys. Chem. A, 1989, 93, 495.

71 M. Liu, C. Luo, R. Huang, H. Peng, Y. Wang and J. TravasSejdic, Int. J. Polym. Mater. Polym. Biomater., 2014, 63, 602.

72 Y. Yang, Y. Min, J. C. Wu, D. J. Hansford, S. E. Feinberg and A. J. Epstein, Macromol. Rapid Commun., 2011, 32, 887.

73 S. Kamalesh, P. Tan, J. Wang, T. Lee, E. T. Kang and C. H. Wang, J. Biomed. Mater. Res., Part A, 2000, 52, 467.

74 Y. Liu, S. B. Li, P. Yao and Q. M. Zhang, Int. J. Mod. Phys. B, 2017, 31, 1744091.

75 R. Guo, J. N. Barisci, P. C. Innis, C. O. Too, G. G. Wallace and D. Zhou, Synth. Met., 2000, 114, 267.

76 V. Prevost, A. Petit and F. Pla, Synth. Met., 1999, 104, 79.

77 P. Román, R. Cruz-Silva and R. Vazquez-Duhalt, Synth. Met., 2012, 162, 794.

78 J. Huang and R. B. Kaner, J. Am. Chem. Soc., 2004, 126, 851. 79 H. Goto, Macromol. Chem. Phys., 2006, 207, 1087.

80 B. Gupta and R. Prakash, Macromol. Chem. Phys., 2012, 213, 1457. 
81 S. Xiong, Y. Shi, S. Chen, J. Li, X. Wang, J. Chu and B. Wu, J. Appl. Polym. Sci., 2014, 131, 40666.

82 A. Falcou, A. Longeau, D. Marsacq, P. Hourquebie and A. Duchene, Synth. Met., 1999, 101, 647.

83 G. Zotti, N. Comisso, G. D'Aprano and M. Leclerc, Adv. Mater., 1992, 4, 749.

84 S. Xu, S. Ogi, K. Sugiyasu, S. Sumi, Y. Kobayashi and M. Takeuchi, J. Nanosci. Nanotechnol., 2014, 14, 4449.

85 A. Gök, B. Sarı and M. Talu, Synth. Met., 2004, 142, 41.

86 A. K. Behera, B. Adhikari and P. Kar, Polym. Sci., Ser. B+, 2015, 57, 159.

87 S. Ito, K. Murata, S. Teshima, R. Aizawa, Y. Asako, K. Takahashi and B. M. Hoffman, Synth. Met., 1998, 96, 161.

88 K. Takahashi, K. Nakamura, T. Yamaguchi, T. Komura, S. Ito, R. Aizawa and K. Murata, Synth. Met., 2002, 128, 27. 89 B. A. Deore and M. S. Freund, Macromolecules, 2008, 42, 164. 90 V. N. Nikitina, I. R. Kochetkov, E. E. Karyakina, A. K. Yatsimirsky and A. A. Karyakin, Electrochem. Commun., 2015, 51, 121.

91 B. A. Deore, I. Yu, M. S. Freund, US Pat., 8658759, 2014.

92 B. A. Deore, I. Yu, P. M. Aguiar, C. Recksiedler, S. Kroeker and M. S. Freund, Chem. Mater., 2005, 17, 3803.

93 B. A. Deore, I. Yu, J. Woodmass and M. S. Freund, Macromol. Chem. Phys., 2008, 209, 1094.

94 J. Yue, Z. H. Wang, K. R. Cromack, A. J. Epstein and A. G. MacDiarmid, J. Am. Chem. Soc., 1991, 113, 2665.

95 J. Stejskal, I. Sapurina and M. Trchova, Prog. Polym. Sci., 2010, 35, 1420.

96 T. A. Skotheim and J. Reynolds, in Conjugated polymers: theory, synthesis, properties, and characterization, CRC Press, 2006, p. 1024.

97 S. Tarasevich and E. Orlov, Shkolnikov Electrochemistry of polymers, Science, Moscow, 1990.

98 M. Sahin, L. Özcan, A. Özcan, B. Usta, Y. Sahin and K. Pekmez, J. Appl. Polym. Sci., 2010, 115, 3024.

99 G. Ćirić-Marjanović, Synth. Met., 2013, 177, 1.

100 E. M. Genies and P. Noel, J. Electroanal. Chem. Interfacial Electrochem., 1991, 310, 89.

101 Y. Z. Su, W. Dong, J. H. Zhang, J. H. Song, Y. H. Zhang and K. C. Gong, Polymer, 2007, 48, 165.

102 C. Su, L. Ji, L. Xu, X. Zhu, H. He, Y. Lv and C. Zhang, RSC $A d v ., 2015,5,14053$.

103 W. A. Christinelli, L. G. da Trindade, A. B. Trench, C. S. Quintans, C. M. Paranhos and E. C. Pereira, Energy, 2017, 141, 1829.

104 K. M. Molapo, P. M. Ndangili, R. F. Ajayi, G. Mbambisa, S. M. Mailu, N. Njomo and E. I. Iwuoha, Int. J. Electrochem. Sci., 2012, 7, 11859.

105 S. J. Pomfret, P. N. Adams, N. P. Comfort and A. P. Monkman, Polymer, 2000, 41, 2265.

106 F. Cataldo and P. Maltese, Eur. Polym. J., 2002, 38, 1791.

107 T. V. Shishkanova, M. Havlík, V. Král, D. Kopecký, P. Matějka, M. Dendisová and V. M. Mirsky, Electrochim. Acta, 2017, 224, 439.

108 P. Anilkumar and M. Jayakanna, Langmuir, 2008, 24, 9754. 109 S. Jadoun, A. Verma, S. M. Ashraf and U. Riaz, Colloid Polym. Sci., 2017, 295, 1443.
110 S. Samanta, P. Roy and P. Kar, Macromol. Res., 2016, 24, 342.

111 S. Samanta, P. Roy and P. Kar, Polym. Adv. Technol., 2017, 28, 797.

112 D. P. Kang and M. S. Yun, Synth. Met., 1989, 29, 343.

113 S. Bilal and R. Holze, Synth. Met., 2012, 162, 356.

114 M. Fabrizio, G. Mengoli, M. M. Musiani and F. Paolucci, Synth. Met., 1991, 44, 271.

115 F. R. Diaz, C. O. Sánchez, M. A. Del Valle, L. H. Tagle, J. C. Bernede and Y. Tregouet, Synth. Met., 1998, 92, 99.

116 L. L. Rubio, M. M. Castillo-Ortega, L. Rejon, R. Olayo and G. J. Cruz, J. Polym. Sci., Part B: Polym. Phys., 2002, 40, 2130.

117 J. Yue and A. J. Epstein, J. Am. Chem. Soc., 1990, 112, 2800.

118 H. Salavagione, G. M. Morales, M. C. Miras and C. Barbero, Acta Polym., 1999, 50, 40.

119 S. Atkinson, H. S. O. Chan, A. J. Neuendorf, S. C. Ng, T. T. Ong and D. J. Young, Chem. Lett., 2000, 276.

120 T. C. Tsai, D. A. Tree and M. S. High, Ind. Eng. Chem. Res., 1994, 33, 2600.

121 H. S. O. Chan, P. K. H. Ho, S. C. Ng, B. T. G. Tan and K. L. Tan, J. Am. Chem. Soc., 1995, 117, 8517.

122 T. C. Wen, L. M. Huang and A. Gopalan, Electrochim. Acta, 2001, 46, 2463.

123 A. Gök and B. Sari, J. Appl. Polym. Sci., 2002, 84, 1993.

124 A. K. Singh, R. Prakash, A. D. D. Dwivedi and P. Chakrabarti, Synth. Met., 2008, 158, 939.

125 B. Gupta, A. Melvin and R. Prakash, Bull. Mater. Sci., 2014, 37, 1389.

126 A. K. Singh, R. Prakash, A. D. D. Dwivedi and P. Chakrabarti, IEEE Electron Device Lett., 2008, 29, 571.

127 J. Prokeš and J. Stejskal, Polym. Degrad. Stab., 2004, 86, 187.

128 N. Chandrakanthi and M. A. Careem, Polym. Bull., 2000, 44, 101.

129 B. Sreedhar, M. Sairam, D. K. Chattopadhyay, P. P. Mitra and D. M. Rao, J. Appl. Polym. Sci., 2006, 101, 499.

130 H. D. Tran, J. M. D'Arcy, Y. Wang, P. J. Beltramo, V. A. Strong and R. B. Kaner, J. Mater. Chem., 2011, 21, 3534.

131 J. Huang and R. B. Kaner, Chem. Commun., 2006, 367.

132 H. D. Tran, I. Norris, J. M. D'Arcy, H. Tsang, Y. Wang, B. R. Mattes and R. B. Kaner, Macromolecules, 2008, 41, 7405.

133 P. Liu and L. Zhang, Crit. Rev. Solid State Mater. Sci., 2009, 34, 75.

134 H. D. Tran, D. Li and R. B. Kaner, Adv. Mater., 2009, 21, 1487.

135 J. Sui, L. Z. Zhang, H. Peng, J. Travas-Sejdic and P. Kilmartin, Nanotechnology, 2009, 20, 415606.

136 R. Jamal, T. Abdiryim and I. Nurulla, Polym Adv Tech., 2008, 19, 1461.

137 A. Gök, B. Sarı and M. Talu, Synth. Met., 2004, 142, 41.

138 D. Li and R. B. Kaner, J. Mater. Chem., 2007, 17, 2279.

139 J. Huang and R. B. Kaner, Angew. Chem., 2004, 116, 5941.

140 D. Li, J. Huang and R. B. Kaner, Acc. Chem. Res., 2008, 42, 135.

141 I. Sapurina, A. Riede and J. Stejskal, Synth. Met., 2001, 123, 503. 
142 M. Abdollahi, M. R. Yousefi, P. Alamdari, H. Ranjbar, F. S. Najafi and F. Rekabdar, Int. J. Clin. Pharmacol. Toxicol., 2013, 1, 1.

143 B. Suppaibulsuk, G. L. Rempel and P. Prasassarakich, Polym. Adv. Technol., 2011, 13, 1473.

144 G. Wu, C. Wang, Z. Tan and H. Zhang, Prod. Eng., 2011, 18, 353.

145 N. Paradee and A. Sirivat, Polym. Int., 2014, 63, 106.

146 R. J. Kline and M. D. McGehee, J. Macromol. Sci., Polym. Rev., 2006, 46, 27.

147 S. I. Heo, J. C. Yun, O. KS and K. S. Han, Adv. Compos. Mater., 2006, 15, 115.

148 M. E. Vaschetto and B. A. Retamal, J. Phys. Chem. A, 1997, 101, 6945.

149 M. E. Vaschetto, B. A. Retamal and A. P. Monkman, J. Mol. Struct.: THEOCHEM, 1999, 468, 209.

150 N. A. Zaidi, J. P. Foreman, G. Tzamalis, S. C. Monkman and A. P. Monkman, Adv. Funct. Mater., 2004, 14, 479.

151 X. P. Chen, J. K. Jiang, Q. H. Liang, N. Yang, H. Y. Ye, M. Cai and T. L. Ren, Sci. Rep., 2015, 5, 16907.

152 Y. Zhang, Y. Duan, L. Song, D. Zheng, M. Zhang and G. Zhao, J. Chem. Phys., 2017, 147, 114905.

153 K. M. Molapo, P. M. Ndangili, R. F. Ajayi, G. Mbambisa, S. M. Mailu, N. Njomo and E. I. Iwuoha, Int. J. Electrochem. Sci., 2012, 7, 11859.

154 K. Crowley, M. R. Smyth, A. J. Killard and A. Morrin, Chem. Pap., 2013, 67, 771.

155 P. N. Bartlett and S. K. Ling-Chung, Sens. Actuators, 1989, 20, 287.

156 N. E. Agbor, M. C. Petty and A. P. Monkman, Sens. Actuators, $B$, 1995, 28, 173.

157 P. S. Barker, J. R. Chen, N. I. Agbor, A. P. Monkman, P. Mars and M. C. Petty, Sens. Actuators, B, 1994, 17, 143.

158 A. I. Gopalan, S. Komathi, N. Muthuchamy, K. P. Lee, M. J. Whitcombe, D. Lakshmi and G. Sai-Anand, Prog. Polym. Sci., 2019, 88, 1.

159 E. Pringsheim, E. Terpetschnig and O. S. Wolfbeis, Anal. Chim. Acta, 1997, 357, 247.

160 E. Shoji and M. S. Freund, J. Am. Chem. Soc., 2001, 123, 3383.

161 E. Shoji and M. S. Freund, J. Am. Chem. Soc., 2002, 124, 12486

162 P. Huh, S. C. Kim, Y. Kim, Y. Wang, J. Singh, J. Kumar and J. O. Lee, Biomacromolecules, 2007, 8, 3602.

163 E. Pringsheim, E. Terpetschnig, S. A. Piletsky and O. S. Wolfbeis, Adv. Mater., 1999, 11, 865.

164 B. A. Deore and M. S. Freund, Chem. Mater., 2005, 17, 2918. 165 S. R. Ali, Y. Ma, R. R. Parajuli, Y. Balogun, W. Y. C. Lai and H. He, Anal. Chem., 2007, 79, 2583.

166 B. Fabre and L. Taillebois, Chem. Commun., 2003, 2982.

167 G. Li, Y. Li, H. Peng and K. Chen, Macromol. Rapid Commun., 2011, 32, 1195.

168 E. A. Andreyev, M. A. Komkova, V. N. Nikitina, N. V. Zaryanov, O. G. Voronin, E. E. Karyakina and A. A. Karyakin, Anal. Chem., 2014, 86, 11690.

169 D. Ragupathy, A. I. Gopalan, K. P. Lee and K. M. Manesh, Electrochem. Commun., 2008, 10, 527.
170 Y. Tian, K. Qu and X. Zeng, Sens. Actuators, B, 2017, 249, 423.

171 A. A. Athawale and M. V. Kulkarni, Sens. Actuators, B, 2000, 67, 173.

172 H. Cankurtaran, O. Yazici, S. Dinc and F. Karaman, Int. J. Electrochem. Sci., 2013, 8, 3265.

173 M. H. Ansari, J. B. Parsa and J. Arjomandi, Sep. Purif. Technol., 2017, 179, 104.

174 S. Ahmad, S. M. Ashraf, U. Riaz and S. Zafar, Prog. Org. Coat., 2008, 62, 32.

175 U. Riaz, S. A. Ahmad, S. M. Ashraf and S. Ahmad, Prog. Org. Coat., 2009, 65, 405.

176 D. Sazou, Synth. Met., 2001, 118, 133.

177 S. Sathiyanarayanan, V. Karpakam, K. Kamaraj, S. Muthukrishnan and G. Venkatachari, Surf. Coat. Technol., 2010, 204, 1426.

178 K. Kamaraj, V. Karpakam, S. Sathiyanarayanan and G. Venkatachari, Mater. Chem. Phys., 2010, 122, 123.

179 W. Cai, J. Wang, X. Quan, S. Zhao and Z. Wang, Surf. Coat. Technol., 2018, 334, 7.

180 U. Riaz and S. M. Ashraf, Int. J. Polym. Mater., 2013, 62, 406. 181 G. A. Snook, P. Kao and A. S. Best, J. Power Sources, 2011, 196, 1.

182 S. R. Sivakkumar and R. Saraswathi, J. Power Sources, 2004, 137, 322.

183 K. S. Ryu, K. M. Kim, N. G. Park, Y. J. Park and S. H. Chang, J. Power Sources, 2002, 103, 305.

184 H. Talbi, P. E. Just and L. H. Dao, J. Appl. Electrochem., 2003, 33, 465.

185 K. S. Ryu, K. M. Kim, Y. J. Park, N. G. Park, M. G. Kang and S. H. Chang, Solid State Ionics, 2002, 152, 861.

186 P. Gómez-Romero, M. Chojak, K. Cuentas-Gallegos, J. A. Asensio, P. J. Kulesza, N. Casañ-Pastor and M. LiraCantú, Electrochem. Commun., 2003, 5, 149.

187 P. J. Kulesza, M. Skunik, B. Baranowska, K. Miecznikowski, M. Chojak, K. Karnicka and B. Starobrzynska, Electrochim. Acta, 2006, 51, 2373.

188 K. S. Ryu, Y. G. Lee, K. M. Kim, Y. J. Park, Y. S. Hong, X. Wu and J. M. Ko, Synth. Met., 2005, 153, 89.

189 V. Khomenko, E. Frackowiak and F. Beguin, Electrochim. Acta, 2005, 50, 2499.

190 J. Zhang, D. Shan and S. Mu, J. Power Sources, 2006, 161, 685

191 H. Talbi, P. E. Just and L. H. Dao, J. Appl. Electrochem., 2003, 33, 465.

192 P. A. Basnayaka, F. Alvi, M. K. Ram, R. Tufts and A. Kumar, Mater. Res. Soc. Symp. Proc., 2012, 1388, Mrsf11-1388-f1104.

193 A. Thota, R. Arukula, R. Narayan, C. R. Rao and K. V. S. N. Raju, RSC Adv., 2015, 5, 106523.

194 M. R. Gizdavic-Nikolaidis, J. R. Bennett, S. Swift, A. J. Easteal and M. Ambrose, Acta Biomater., 2011, 7, 4204.

195 M. R. Gizdavic-Nikolaidis, J. C. Pagnon, N. Ali, R. Sum, N. Davies, L. F. Roddam and M. Ambrose, Colloids Surf., $B$, 2015, 136, 666 .

196 M. S. Lashkenari, H. Eisazadeh and M. Rahimnejad, Polycyclic Aromat. Compd., 2014, 34, 620. 
197 M. R. Gizdavic-Nikolaidis, S. Ray, J. Bennett, A. J. Easteal and R. P. Cooney, Macromol. Biosci., 2010, 10, 1424.

198 M. Gizdavic-Nikolaidis, S. Ray, J. Bennett, S. Swift, G. A. Bowmaker and A. J. Easteal, J. Polym. Sci., Part A: Polym. Chem., 2011, 49, 4902.

199 M. R. Gizdavic-Nikolaidis, J. Bennett, Z. Zujovic, S. Swift and A. J. Easteal, Synth. Met., 2012, 162, 1114.

200 J. Robertson, J. Dalton, S. Wiles, M. Gizdavic-Nikolaidis and S. Swift, PeerJ, 2016, 4, e2795.

201 M. S. Lashkenari, H. Eisazadeh and M. Rahimnejad, Polycyclic Aromat. Compd., 2014, 34, 620.

202 J. Wang, L. H. Zhu, J. Li and H. Q. Tang, Chin. Chem. Lett., 2007, 18, 1005.

203 S. Banerjee, J. P. Saikia, A. Kumar and B. K. Konwar, Nanotechnology, 2009, 21, 045101.
204 M. Gizdavic-Nikolaidis, J. Travas-Sejdic, G. A. Bowmaker, R. P. Cooney, C. Thompson and P. A. Kilmartin, Curr. Appl. Phys., 2004, 4, 347.

205 M. Gizdavic-Nikolaidis, J. Travas-Sejdic, G. A. Bowmaker, R. P. Cooney and P. A. Kilmartin, Synth. Met., 2004, 140, 225.

206 C. F. Hsu, H. HPeng, L. Zhang, J. Travas-Sejdic and P. A. Kilmartin, e-J. Surf. Sci. Nanotechnol., 2009, 7, 269.

207 A. Nasar and F. Mashkoor, Environ. Sci. Pollut. Res., 2019, 26, 5333.

208 H. Lei, N. Pan, X. Wang and H. Zou, J. Chem. Eng. Data, 2018, 63, 3989.

209 S. Majumdar, A. Baishya and D. Mahanta, Fibers Polym., 2019, 20, 1226.

210 K. Zhang, J. Wang, Y. Wang, L. Zhao and Q. Xu, Chem. Eng. J., 2014, 247, 50. 